Article

\title{
Fire Severity and Vegetation Recovery on Mine Site Rehabilitation Using WorldView-3 Imagery
}

\author{
Phillip McKenna ${ }^{1, *}$, Stuart Phinn ${ }^{2}$ (D) and Peter D. Erskine ${ }^{1}$ \\ 1 Centre for Mined Land Rehabilitation, Sustainable Minerals Institute, The University of Queensland, \\ Brisbane, QLD 4072, Australia; p.erskine@uq.edu.au \\ 2 Remote Sensing Research Centre, School of Earth and Environmental Sciences, \\ The University of Queensland, Brisbane, QLD 4072, Australia; s.phinn@uq.edu.au \\ * Correspondence: p.mckenna@cmlr.uq.edu.au
}

Received: 6 April 2018; Accepted: 2 July 2018; Published: 3 July 2018

\begin{abstract}
As open-cut coal mines progress towards closure, mining companies have an obligation to provide certainty to stakeholders that their rehabilitated landscapes have the capacity to withstand future disturbance impacts such as fire and drought. This paper describes the assessment of fire severity and recovery using WorldView-3 spectral indices following an experimental fire in a 19- to 21-year old coal mine rehabilitation in semi-arid Central Queensland, Australia. In a highly heterogeneous reconstructed environment, the differenced Normalized Difference Vegetation Index ( $d \mathrm{NDVI}$ ) outperformed the differenced Normalized Burn Ratio $(d \mathrm{NBR})$ with an overall map accuracy of $65 \%$ and $58 \%$, respectively. The combination of red and near infra-red multispectral bands proved more effective at classifying severity compared with the shortwave infra-red, particularly when pre-fire imagery was dominated by highly cured grasses $(>70 \%)$ and post-fire imagery contained a high coverage of residual ash. Recovery trends using spectral indices demonstrate the trajectory towards vegetation recovery, with $62 \%$ of the burnt site demonstrating high regrowth in the first two years following fire. This is supported by in situ recovery trends of understory biomass suggesting that under the study conditions, the rehabilitated site has the capacity to withstand impacts from a wildfire and recover to pre-fire levels.
\end{abstract}

Keywords: pasture; fire exclusion; satellite; reclamation; resilience; mine relinquishment; Australia; remote sensing

\section{Introduction}

Rehabilitation of open-cut coal mines in Queensland, Australia, is an obligation under state legislation. Prior to lease relinquishment, mining companies are required to demonstrate that rehabilitation is safe, stable, self-sustainable and non-polluting [1]. Considering that fire is a common, natural and important occurrence in the Australian landscape [2], it is inevitable that at some future point, mine site rehabilitation will be subject to wildfire disturbance.

In Central Queensland, mine managers in areas such as the Bowen Basin require methods to manage fire risk, and demonstrate to regulators and future land-holders that rehabilitated ecosystems have the capacity to withstand fire impacts. This is vital given that the risk of fire on rehabilitated areas may be increased due to: (i) the widespread planting of high biomass pasture grasses such as buffel grass (Cenchrus ciliaris L.) [3,4]; (ii) relatively steep sloping landforms (compared to pre-mining) to minimize mine footprints [5]; and (iii) the general policy of fire exclusion leading to the accumulation of unmanaged high fuel loads over more than 20 years [3,4,6]. As mines move towards closure and lease relinquishment, it is therefore reasonable that mines demonstrate the resilience and ecological recovery 
of rehabilitated areas to disturbances using monitoring methods that are accepted as scientifically robust, repeatable and valid.

Typically, ecological assessments of mine site rehabilitation have involved ground surveys of multiple small plots (e.g., $400 \mathrm{~m}^{2}$ ) that are assumed to be representative of larger areas [7] but can be costly and time-consuming to complete. While the application of remote sensing techniques to mine site rehabilitation has been recognized [8,9], the number of peer reviewed studies is limited to a few that demonstrate vegetation cover development $[7,10-12]$ and fire severity using Unmanned Aerial Vehicles (UAVs) [13]. To date, no studies have used high spatial, spectral and temporal resolution satellite imagery to assess fire impacts and vegetation recovery on mine site rehabilitation at the local or regional scale. As a consequence, rehabilitation managers have limited understanding of the potential remote sensing techniques that may be applicable to demonstrate the stability and resilience of rehabilitation to fire. By demonstrating this resilience, managers have the opportunity to reduce reputational and financial risk and in some cases fast-track lease relinquishment at mine closure.

\subsection{Remote Sensing Approaches to Fire Severity Mapping and Fire Recovery}

Mapping the fire perimeter location and classifying fire severity using remote sensing was first demonstrated using sensors on the early Landsat series satellites (Multispectral Scanner (MSS)/Thematic Mapper (TM)/Enhanced Thematic Mapper Plus (ETM+)) [14-16] and sensors such as the Advanced Very High Resolution Radiometer (AVHRR) carried out by the National Oceanic and Atmospheric Administration (NOAA) satellites [17]. Since then, published literature is dominated with case studies using spectral indices such as the Normalized Burn Ratio (NBR) and Normalized Differenced Vegetation Index (NDVI) from a variety of sensors to infer fire impacts and vegetative recovery [18]. Importantly, definitions of fire terminology amongst remote sensing scientists and fire ecologists have been a matter of ongoing discussion and debate $[15,19,20]$. While short- and long-term fire effects on an ecosystem can be viewed as a severity and recovery continuum [20,21], it is generally accepted that fire severity can be defined as the degree of environmental change caused by direct fire impacts, and is a measurement of the immediate effects on an ecosystem. Additionally, burn severity refers to the short- and long-term environmental change caused by the fire $[15,22]$ and requires extended assessments to quantify and characterize.

NBR is the normalized difference between the reflectance values of the near infra-red (NIR) and the short wave infra-red (SWIR) bands [14,15], while NDVI is the normalized difference between the reflectance values of the NIR and the red bands [23,24]. Although reflectance in the Red, NIR and SWIR regions of the electromagnetic spectrum (EMS) is driven by different biophysical factors [25], the NBR and NDVI can behave in a broadly similar way. For example, both indices show strongly positive values when ground features are dominated by high biomass and green vegetation, while values close to zero indicate that vegetation is sparse, dead, or highly cured. Conversely, negative values indicate exposed soil and very low vegetation cover $[15,26,27]$.

By extending the NBR and NDVI, bi-temporal indices such as the differenced Normalized Burn Ratio $(d \mathrm{NBR})$ and the differenced Normalized Differenced Vegetation Index ( $d \mathrm{NDVI}$ ) increase the power to measure absolute changes by using imagery captured in pre-fire and post-fire dates [15]. Compared with the NBR and NDVI, the reflectance scale for the differenced rasters ( $d$ NBR and $d$ NDVI) is inverted. High raster values indicate a relatively greater change from pre-fire values (reduced vegetation cover and drying of surface), while raster values around zero represent negligible fire impacts. With extended temporal assessments, strongly negative raster values for $d \mathrm{NBR}$ and $d \mathrm{NDVI}$ represent increasing vegetation regrowth $[15,18]$.

The vast majority of remote sensing studies applying the fire indices $d$ NBR and $d$ NDVI have been conducted in heavily forested environments in the northern hemisphere [18,28-30]. In the southern hemisphere, Australian studies have demonstrated fire severity and recovery in a range of environments: in tropical savannas [31,32], and in dry sclerophyll eucalypt forests in eastern [33-36] and Western Australia [37,38]. 


\subsection{Spectral Responses to Fire}

An understanding of the changes in magnitude of spectral reflectance within the EMS following fire is fundamental to fire severity mapping using remote sensing $[15,27]$. While visible wavelengths (Red, Green, Blue) demonstrate measurable changes [39], the largest post-fire changes occur in the NIR and SWIR regions of the EMS due to the loss of vegetative cover and the exposure and drying of underlying soil $[14,15,31,32,40]$. NIR shifts to a notably lower reflectance with a loss of vegetation while SWIR reflectance values have been shown to increase with increasing fire severity [15,41]. However, responses to fire across the EMS are highly variable depending on biogeographical region, vegetation type and pre-fire vegetation condition [18,32]. The success of indices such as $d$ NDVI and $d$ NBR is related to vegetation type [18], with forested environments generally producing greater map accuracies and regression relationships when compared with results for studies conducted in grasslands [42,43], swamps [34] and heathlands [36].

The SWIR bands most widely used for the NBR index are centered around $2100 \mathrm{~nm}$ (Band 7 on Landsat TM/ETM+/Operational Land Imager (OLI) as this region shows the greatest variance within burns [15]. The longer wavelengths sampled in the SWIR can be used to measure spectral responses relating to soil exposure and changes in soil moisture $[15,25]$ as well as a loss of vegetation moisture through leaf water content loss $[25,41,44]$. While water content in vegetation is the primary driver of spectral reflectance in SWIR [44], the loss of water results in the dominance of lignin and cellulose (present in plant cell walls) as a key feature determining spectral reflectance (particularly in region of 2100-2300 nm) $[45,46]$. The loss of vegetation water content and the drying, curing and senescence of grasslands results in higher reflectance in the SWIR region compared with green grass and green canopies [26,31,32,42].

The spectral reflectance of post-fire ash has been directly related to fire intensity and combustion of available fuels [43]. White ash indicates a high rate of combustion and is characterized by a high reflective signature across the EMS. Black ash is generally depicted by a flat and featureless spectral reflectance signature and represents a lower burn intensity and lower fuel combustion $[43,47,48]$. Other studies have shown spectral variability of post-fire ash qualities depending on vegetation type, degree of combustion and wildfire location [49].

In this study, we applied fire to a 19- to 21-year old rehabilitated mine site and measured the vegetation response using spectral indices, along with ground assessments to validate imagery and support remote sensing findings. Since remote sensing is currently underutilized by rehabilitation practitioners, we aimed to demonstrate the most effective spectral indices to quantify disturbance and vegetation recovery in the study region, and thereby encourage rehabilitation managers to further employ remote sensing techniques in the pursuit of site relinquishment. The first objective of this study was to assess the viability of using WorldView-3 spectral indices $d$ NDVI and $d$ NBR to characterize fire severity and regeneration of post-mined landscapes at local scales $(\sim 1 \mathrm{~m}$ and $\sim \mathrm{m}$ pixels over $<10 \mathrm{~km}^{2}$ ). The second objective was to investigate the resilience of mine site rehabilitation to fire impacts, by demonstrating the site recovery trends using spectral indices NDVI and NBR supported by vegetation recovery measured in field sampling. The third objective was to discuss the effectiveness of NDVI and NBR within the study region by generating WorldView-3, 16-band spectral signatures of selected ground features in the burn and control areas.

\section{Materials and Methods}

\subsection{Study Area}

The experimental site is located in the Bowen Basin, Central Queensland, $200 \mathrm{~km}$ west of Rockhampton and $16 \mathrm{~km}$ north of the town of Blackwater (Figure 1). The climate in the region is semi-arid, with a distinct wet and dry season, with an average annual rainfall of $533 \mathrm{~mm}$ [50], predominantly falling in the summer months (December-March); the remainder of the year is relatively dry with lower rainfall totals. 


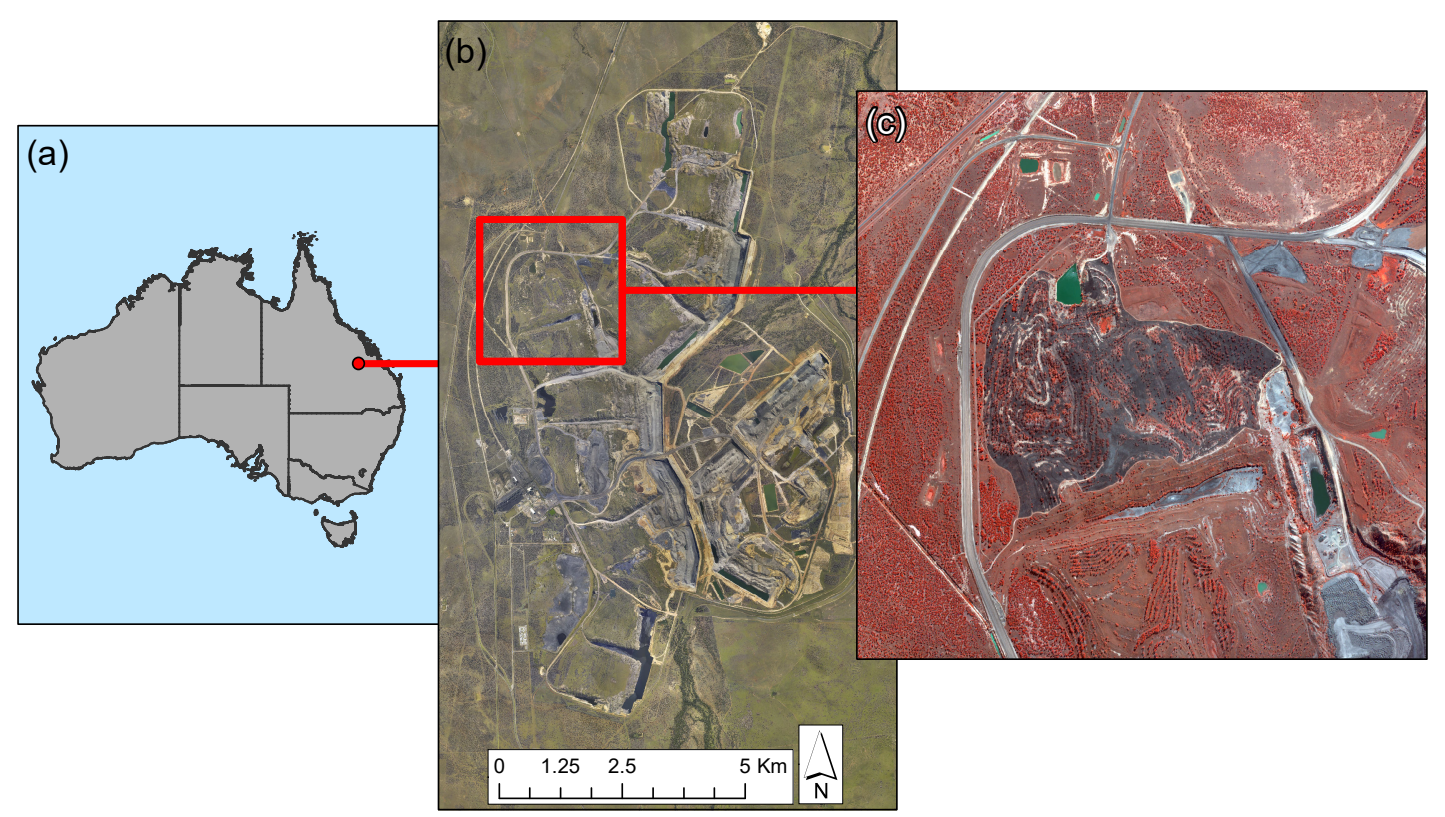

Figure 1. Location of study area (a) Central Queensland study location; (b) aerial image showing mine extent and (c) study site fire scar visible in post-fire WorldView-3 image (7-3-2 band combination).

\subsection{Study Design}

The study was designed to test and demonstrate vegetation resilience and recovery at the transect scale $\left(400 \mathrm{~m}^{2}\right)$ and landscape scale $\left(1-10 \mathrm{~km}^{2}\right)$; and as such uses a combination of field sampling and remote sensing techniques discussed below, represented schematically in Figure 2. Prior to the fire, the study site was stratified into two different vegetation communities using ArcGIS 10.2 (ESRI, Redlands, CA, USA); herein called 'grassland' and 'open woodland' (Figure 3a). These areas were defined by using: (i) historical aerial imagery (taken in 1996) showing topsoil distribution and rehabilitation techniques; and (ii) a 2013 aerial image where grassland and open woodland vegetation communities were clearly visible for digitization using digital aerial photographic interpretation (API) [4]. Over the 19- to 21-years since establishment, areas that were rehabilitated using a cover of $100 \%$ topsoil across the landform developed into a grassland community, while areas that received topsoil coverage in $10 \mathrm{~m}$ wide strips along the contour developed into open woodland communities. Grassland areas were dominated by the invasive, high biomass buffel grass, while open woodland areas consisted of a low density $\left(<1000\right.$ stems ha $\left.{ }^{-1}\right)$ of predominantly two evergreen Acacia species: Acacia stenophylla and A. salicina. Other evergreen canopy species found across the site included Corymbia citriodora subsp. citriodora, Eucalyptus populnea, E. thozetiana and Casuarina cristata.

On 28 May 2015, a controlled experimental fire burnt 117 ha of 19- to 21-year old coal-mine site rehabilitation. Field practitioners attempted to mimic wildfire conditions by burning a large area $(>100 \mathrm{ha})$ in a single fire event; with the fire able to move unhindered with the wind in order to create a mosaic of severity outcomes. The resulting fire behavior and site conditions for the experiment are discussed in previous studies [4]. WorldView-3 satellite imagery was captured for the time-series, including three post-fire images (Figure 3). Color infra-red imagery shows the fire scar from the burn, as well as the regrowth and greening of vegetation within the burn area and the control sites. The patterns of ash within grassland areas indicate that these areas received a relatively homogenous burn of high severity when compared with the open woodland areas that contained residual green canopies and unburnt areas associated with bare areas (Figure 3c). 


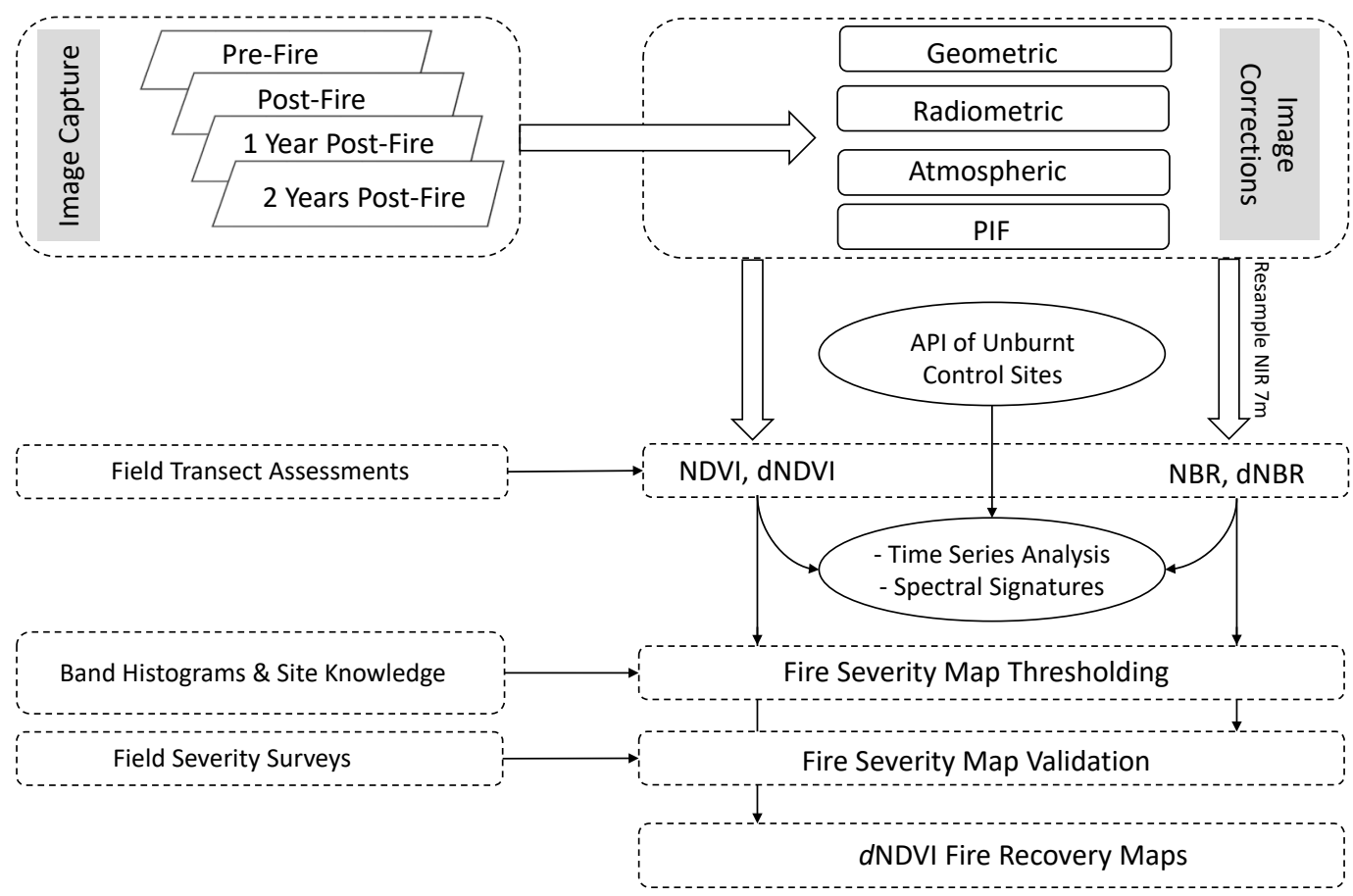

Figure 2. Schematic work flow diagram illustrating the methods used to generate fire severity and recovery maps following the fire and WorldView-3 image capture events.

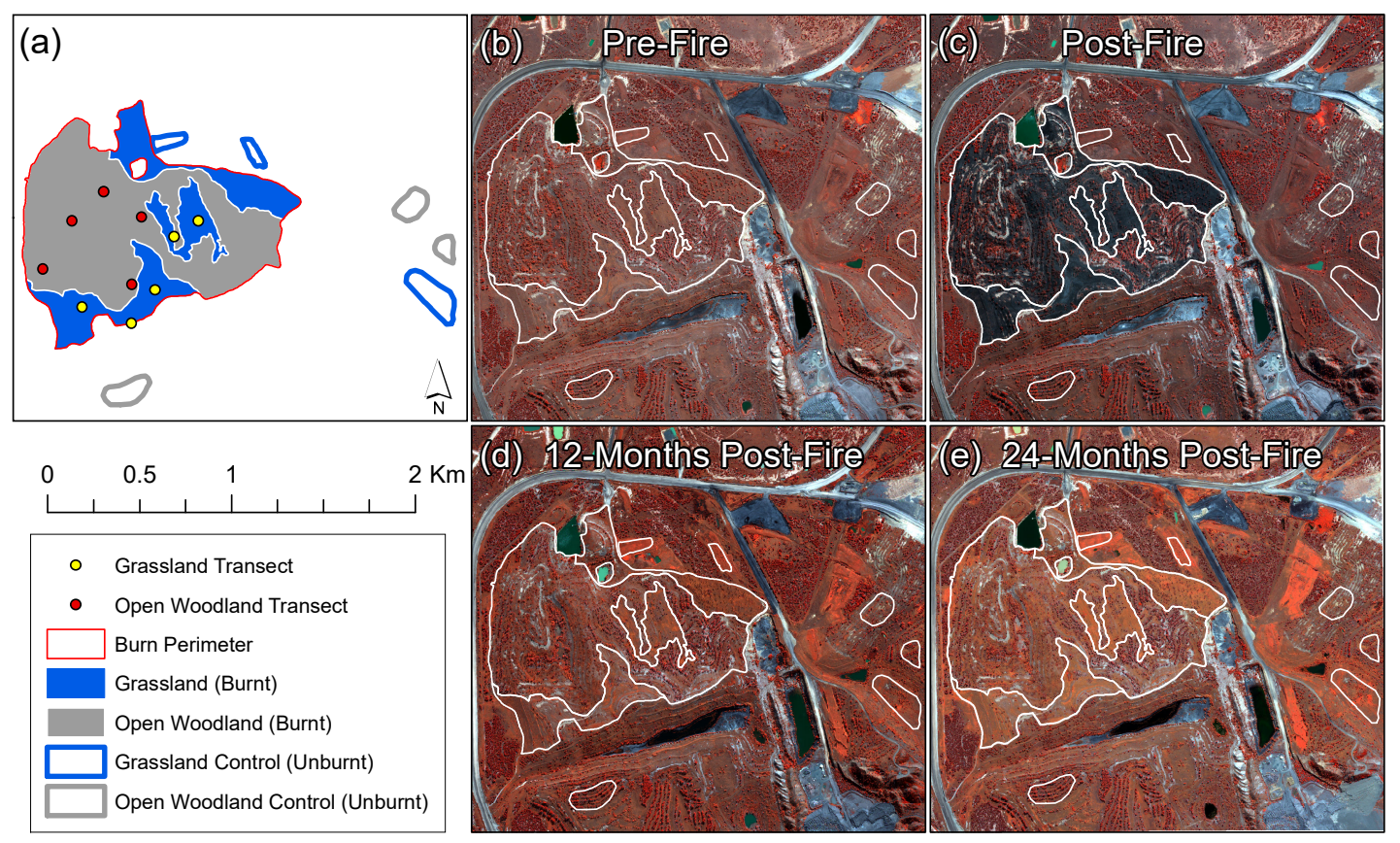

Figure 3. Fire study site illustrating (a) grassland and open woodland vegetation communities within burn perimeter, locations of monitoring transects and control areas outside of burnt perimeter; and WorldView-3 color infra-red time-series images (7-3-2 band combination): (b) pre-fire captured the day prior to the burn; (c) post-fire captured six days following the burn with fire scar clearly visible; (d) 12-months post-fire and (e) 24-months post-fire. 


\subsection{Field Sampling}

The field sampling conducted throughout the experiment falls into two categories:

(i) Vegetation transects of $50 \mathrm{~m} \times 8 \mathrm{~m}\left(400 \mathrm{~m}^{2}\right)$ for repeat measurements of vegetation metrics throughout the time-series.

(ii) Circular fire severity plots $10 \mathrm{~m}$ radius $\left(314.16 \mathrm{~m}^{2}\right)$ for one-off initial post-fire assessments to validate fire severity maps.

\subsubsection{Vegetation Transect Assessments}

A total of ten transects were randomly assigned within the burnt perimeter, with five transects allocated to grassland areas and five transects placed within the open woodland areas. Transects were oriented downhill in order to capture any vegetation variation due to differences in topsoil coverage. In order to test correlations with spectral indices and support remote sensing findings, the vegetation metrics sampled included: (i) grass curing and (ii) understory biomass in $1 \mathrm{~m} \times 1 \mathrm{~m}$ quadrats as described in [4]. Data were collected on the monitoring transects during time periods that aligned with the dates of image captures.

The grass curing assessment was based on a modified pole method [51]. A red colored laser pointer was attached to a pole and held vertically at each meter along a $50 \mathrm{~m}$ transect. The uppermost leaf of grass that was illuminated was visually characterized as being either 'green' or 'dry'. The total points for each transect were tallied $(n=50)$ and the proportion of dry hits were calculated to determine a curing value for each transect.

Biomass assessments were based on a weight-rank method [52] using a scale of 1-10 at every $5 \mathrm{~m}$ along the $50 \mathrm{~m}$ transect by two observers using $1 \mathrm{~m} \times 1 \mathrm{~m}$ quadrats $(n=10)$. Fifteen quadrat standards across a range of ranks ( 0 to 10$)$ were physically cut, weighed immediately, oven dried (three days at $65^{\circ} \mathrm{C}$ ) and re-weighed to obtain the dry weight. Using these standards, a regression curve was created $\left(r^{2}=0.83\right.$; residual standard error $\left.=2.6 \mathrm{t} / \mathrm{ha}\right)$ and regression formulas were applied to quadrat estimates to calculate tons per hectare dry weight $(t / h a)$. Operator bias was minimized by using the same two observers for the duration of the project, who both visually re-calibrated prior to each monitoring period. Biomass data was collected at monitoring transects in pre-fire, post-fire, 3-, 6-, 12- and 24-months post-fire intervals.

\subsubsection{Fire Severity Plot Assessments}

Fire severity assessments were completed on 17-18 September 2015 ( 3 months following the fire). A draft $d$ NDVI severity map was generated (using raw digital numbers) and a total of 300 waypoints were randomly generated (100 per class) within the burn perimeter. Two observers separately navigated to waypoints and ranked fire impacts within a $10 \mathrm{~m}$ radius circular plot for the metrics listed in Table 1. For the purposes of this study, each stratum was defined by the dominant growth forms [53]. Understory was defined as ground cover associated with grass life forms, typically dominated by buffel grass; midstory entailed shrubs generally less than $2 \mathrm{~m}$ in height, mostly characterized by sparse density of Senna spp.; upperstory was defined as trees and shrubs $>2 \mathrm{~m}$ in height, mostly dominated by Acacia spp., Eucalyptus spp. and Corymbia spp.

Plot centers were mapped using a Trimble Geo7x Global Navigation Satellite System (GNSS) and mapped points were post-processed using the nearest base station Receiver Independent Exchange Format (RINEX) data so that each point was $<10 \mathrm{~cm}$ xyz. Three waypoints were excluded from the assessment, since part of the plot fell outside the burn area, leaving a total of 297 plots. Although fire severity assessments were completed 3 months following the fire, the re-sprouting of understory vegetation was minimal and burnt areas were easily distinguished from unburnt areas. Residual ash and burnt grass stubs were still present, and it was therefore possible to estimate the metrics listed in Table 1. 
Table 1. Data captured though data dictionary in circular plots to assess fire severity.

\begin{tabular}{ccc}
\hline Metric & Data Collected & Data Type \\
\hline \% Understory Burnt & $0-100 \%$ & Continuous \\
Average Grass Stub length & Unburnt, $>5 \mathrm{~cm},<5 \mathrm{~cm},<2 \mathrm{~cm}$ Root Crown & Ordinal \\
$\%$ Midstory Scorched & $0-100 \%$ & Continuous \\
$\%$ Upperstory Scorched & $0-100 \%$ & Continuous \\
Average Char Height & No trees, Unburnt, Bases $<0.5 \mathrm{~m},<1 \mathrm{~m},<2 \mathrm{~m}$ & Ordinal \\
Photos & Captured facing south & - \\
Comments & General observations & Text \\
\hline
\end{tabular}

\subsection{Image Analysis}

The remote sensing methodological processes followed throughout this study can be summarized in the following order: (i) image pre-processing; (ii) calculation of NDVI, $d$ NDVI, NBR and $d$ NBR indices; (iii) fire severity map validation; (iv) time-series recovery map and generation of recovery trajectories; and (v) generation and analysis of spectral signatures for selected ground features (Figure 2). DigitalGlobe's WorldView-3 satellite was the preferred sensor for the project due to the high spatial, temporal and radiometric resolution which were well suited to the small study site. The satellite provided $1.2 \mathrm{~m}$ multispectral and $7.3 \mathrm{~m}$ SWIR spatial resolution and 11 bit and 14 bit radiometric resolution respectively. The added advantage of eight multispectral and eight SWIR bands enabled the generation of spectral signatures of selected ground features; this provided context for the discussion around appropriate wavelengths to determine severity and recovery in the semi-arid environment. Bands and associated wavelengths that were used in the spectral indices included: red (630-690 nm), NIR1 (770-895 nm) and SWIR5 (2145-2185 nm) [54].

\subsubsection{Image Capture}

WorldView-3 imagery was successfully captured in cloud free conditions over the site in four epochs (Table 2, Figure 3). The pre- and post-fire captures were timed to be within a seven-day window of the fire, while the post-fire images aimed to be as close to the 12- and 24-month anniversaries as possible to reduce phenological differences. The mean off-nadir viewing angles were variable for the time-series and ranged from 12.1 to 22.8 degrees for the multispectral sensor and 11.7 to 23.2 degrees for the SWIR sensor. Attempts were made for 6- and 9-month post-fire captures, but these were unsuccessful due to cloud cover.

Table 2. Metadata for the WorldView-3 satellite image captures for the project (MS = multispectral). The date of the fire was the 28 May 2015.

\begin{tabular}{ccccc}
\hline \multirow{2}{*}{ Epoch } & Image Dates & Transect & \multicolumn{2}{c}{ Mean off-Nadir Viewing Angle (Degrees) } \\
\cline { 3 - 5 } & & Assessment Dates & MS & SWIR \\
\hline Pre-Fire & 27 May 2015 & 21-27 May 2015 & 16.4 & 16.0 \\
Post-Fire & 3 June 2015 & 30 May-1 June 2015 & 22.8 & 23.2 \\
12-months post-fire & 23 June 2016 & 19-26 June 2016 & 18.5 & 18.2 \\
24-months post-fire & 17 May 2017 & 15-19 May 2017 & 12.1 & 11.7 \\
\hline
\end{tabular}

\subsubsection{Geometric Corrections}

Ten ground control points (GCPs) were mapped in the field using a Trimble Geo7x GNSS, then post-processed using RINEX files from a local base station so that all points were $<10 \mathrm{~cm}$ positional $(x, y, z)$ accuracy. These GCPs were used to geo-reference the June 2016 image, which was subsequently used as a georeferencing base for other imagery (Table 3). Georeferencing errors were the result of a number of factors including: (i) a highly heterogeneous (topography and vegetation cover) study site due to landform design and rehabilitation methods at time of establishment; and (ii) large off-nadir 
viewing angles that were highly variable between captures, increasing the complexity of geometric corrections for the study area. When root-mean-square error (RMSE) values were deemed excessive, second order polynomials were used to reduce RMSE to acceptable levels without introducing excessive warping in the imagery. While the SWIR geometric corrections resulted in sub-pixel accuracy, there were locations within the multispectral images with an elevated RMSE. Despite this, we are confident that the geometric corrections are suitable for the image differencing and time-series analysis.

Table 3. The georeferencing sequence for WV-3 time-series imagery.

\begin{tabular}{ccccccc}
\hline Steps & Image & Wavelength & Georeferenced to: & \# GCPs & Polynomial Order & RMSE (m) \\
\hline 1 & 12-months post-fire & MS & Field GCPs & 10 & 1st & 2.2 \\
2 & Post-fire & MS & 12-months post-fire & 103 & 2nd & 1.3 \\
3 & Pre-fire & MS & Post-fire & 129 & 2nd & 1.95 \\
4 & 24-months post-fire & MS & 12-months post-fire & 55 & 2nd & 1.96 \\
5 & Pre-fire & SWIR & Pre-fire (MS) & 21 & 2nd & 3.21 \\
6 & Post-fire & SWIR & Post-fire (MS) & 20 & 2nd & 2.13 \\
7 & 12-months post-fire & SWIR & 12-months post-fire (MS) & 20 & 1st & 2.29 \\
8 & 24-months post-fire & SWIR & 24-months post-fire (MS) & 10 & 1st & 6.22 \\
\hline
\end{tabular}

\subsubsection{Radiometric and Atmospheric Corrections}

Radiometric and atmospheric corrections were applied to each raster band according to DigitalGlobe specifications [55]. Raw digital numbers (DN) for each band were converted to at-sensor radiance according to Equation (1):

$$
\mathrm{L}=\text { Gain } \times \mathrm{DN} \frac{(\text { abscal factor })}{(\text { Effective bandwidth })}+\text { Offset }
$$

where $\mathrm{L}$ is at-sensor radiance $\left(\mathrm{W} \mu \mathrm{m}^{-1} \mathrm{~m}^{-2} \mathrm{sr}^{-1}\right.$ ) and Gain and Offset are annual calibration adjustment factors specific to each WorldView-3 raster band. Absolute radiometric calibration factor (abscal factor) and effective bandwidth were provided in the DigitalGlobe metadata IMD file.

Rasters were then converted to top-of-atmosphere reflectance (TOA) to normalize for solar irradiance and sensor radiance according to Equation (2):

$$
\rho(\mathrm{TOA}) \lambda=\frac{\mathrm{L}_{\lambda} \mathrm{d}^{2} \pi}{\mathrm{E}_{\lambda} \operatorname{Cos} \theta \mathrm{s}}
$$

where $\mathrm{L}_{\lambda}$ is the at-sensor radiance $\left(\mathrm{W} \mu \mathrm{m}^{-1} \mathrm{~m}^{-2} \mathrm{sr}^{-1}\right), \mathrm{d}$ is the earth-sun distance (astronomical units), $E_{\lambda}$ is the band averaged exo-atmospheric solar irradiation $\left(\mathrm{W} \mu \mathrm{m}^{-1} \mathrm{~m}^{-2}\right)$ and $\theta$ s is the solar zenith angle.

TOA rasters were converted to at-surface reflectance using the dark pixel subtraction method. Minimum raster values were subtracted from each raster to reduce the additive effects of atmospheric inputs $[55,56]$.

\subsubsection{Image Normalization}

Individual bands used in the calculation of fire indices (Red, NIR1 and SWIR5) were corrected for atmospheric and solar differences using pseudo-invariant features method (PIF) [25,57]. Manual selection of ten dark pixels (taken from coal tailings) and ten bright pixels (taken from bare spoil = sub-surface material that has been brought the surface) in each image were used to generate regression models and normalize atmospheric and solar differences in capture conditions (Figures A1 and A2). These PIF-corrected images were used to calculate vegetation indices and generate fire severity classifications and fire recovery maps. 


\subsubsection{Band Indices}

The NDVI was calculated using the red and NIR1 bands from WorldView-3 to produce a continuous raster with a spatial resolution of $1.2 \mathrm{~m}$ (Equation (3)).

$$
\mathrm{NDVI}=\frac{(\mathrm{NIR} 1-\mathrm{RED})}{(\mathrm{NIR} 1+\mathrm{RED})}
$$

The red band was resampled using pixel averaging to $7.3 \mathrm{~m}$ spatial resolution and along with the SWIR5 band, used to calculate the NBR (Equation (4)). The SWIR5 band was chosen for the NBR calculation, since the wavelengths $(2145-2185 \mathrm{~nm})$ correspond with those used in previous studies to calculate NBR using Landsat ETM+ and OLI imagery [15].

$$
\mathrm{NBR}=\frac{(\mathrm{NIR} 1-\mathrm{SWIR} 5)}{(\mathrm{NIR} 1+\mathrm{SWIR} 5)}
$$

NDVI and NBR rasters were calculated for each epoch: (i) pre-fire; (ii) post-fire; (iii) 12 months post-fire; and (iv) 24 months post-fire. Continuous rasters were scaled to $10^{3}$ resulting in rasters that ranged in values -1000 and +1000 . In both indices, high values indicate areas of high-biomass green vegetation, while low values represent bare areas, burnt areas and water bodies (Figure A4).

\subsubsection{Differenced Indices}

The post-fire images were subtracted from the pre-fire images to generate the differenced image rasters as a measure of absolute change between image captures (Equations (5) and (6)). The differenced rasters range in values -2000 and +2000 , with higher values representing areas of greatest change (high fire severity) and low or negative numbers representing unburnt areas.

$$
\begin{gathered}
d \text { NDVI_1000 }=\text { NDVI_1000 } \\
\text { Pre-Fire }- \text { NDVI_1000 } \\
\text { Post-Fire } \\
\text { NBR_1000 }
\end{gathered}
$$

\subsubsection{Calibration \& Validation}

Differenced images were classified into fire severity classes using the band histogram functions to manually delineate natural breaks; in combination with field observations of burn intensity and severity $[4,15]$. Continuous rasters were reclassified into a map consisting of three classes: unburnt, low severity, and high severity. The choice of two fire severity classes (high and low) was based on previous studies in savanna environments where low canopy cover and reduced photosynthetic material (due to cured grasses) reduced the accuracy of fire severity classifications [21].

Validation of the fire severity maps utilized the percent understory burnt data obtained at 297 severity plots, where each plot was given a field-based severity ranking according to thresholds listed in Table 4 . While many fire severity studies use indices such as the composite burn index (CBI) to average fire impacts across each stratum, we chose to use a quantitative, continuous metric that measured the fire impact directly [58]. This choice was taken since the fire was predominantly a ground fire and was generally limited to this stratum. Therefore, it was assumed that this metric was the most representative of the severity captured in post-fire imagery. Additionally, since the field observations were conducted three months post-fire, it was assumed that due to leaf fall and canopy changes, metrics such as crown and leaf scorch were not representative of severity captured in post-fire imagery $[21,39]$ and as such, canopy metrics were not included in the severity validation. Further, tree density across the site was low in open woodland areas ( $<1000$ stems per hectare) and virtually absent in grassland areas. 
Table 4. Severity rankings based on field observations for percent understory burnt.

\begin{tabular}{cc}
\hline Severity Ranking & \% Understory Burnt \\
\hline High Severity & $80-100$ \\
Low Severity & $10-80$ \\
Unburnt & $0-10$ \\
\hline
\end{tabular}

Severity maps were smoothed using the ArcGIS majority filter to reduce mis-classification of individual pixels within the imagery; with the number of neighbors set to four and the replacement threshold set to majority. Pixel values were extracted from each NDVI and NBR severity map at the 297 plot locations and a frequency table was generated for each map to determine the number of occurrences where field severity classes corresponded with modelled severity class. Validation of the fire severity maps was determined through an error matrix [59]. Following the classification process, polygons for grassland and open woodland areas were used to calculate zonal statistics and area values for the $d$ NDVI classification.

\subsubsection{Fire Recovery Maps}

Recovery maps for the 12- and 24-month post-fire time-steps were generated using NDVI to demonstrate areas of regrowth within the burnt area (Equations (7) and (8)). Strongly negative numbers correspond with increased regrowth, and this can be easily distinguished in grassland areas [15]. The recovery maps maintained the same class thresholds as the severity map (above), and therefore, changes in regrowth can be directly compared with the severity map. Due to the lower classification accuracy for $d \mathrm{NBR}$, the $d \mathrm{NDVI}$ was the only index used to demonstrate recovery at the site (Figure A5).

$$
\begin{aligned}
& d \text { NDVI Recovery Map } 1=\text { NDVI_1000 } \\
& \text { Post-Fire }- \text { NDVI_1000 } 12 \text { months Post-Fire } \\
& \text { NDVI Recovery Map } 2=\text { NDVI_1000 Post-Fire }- \text { NDVI_1000 } 24 \text { months Post-Fire }
\end{aligned}
$$

\subsubsection{Standardization of Control and Study Area}

Unburnt control sites were selected based on field knowledge of rehabilitated areas surrounding the burnt site. Three representative grassland areas totaling 5.7 ha and three areas representing open woodland totaling 5.6 ha were digitized using digital API methods. Grassland areas had a high cover of buffel grass and were selected from historical topsoil dumps and rehabilitated areas to the south of the burnt site, while open woodland areas included areas of rehabilitation of similar age and species mix (predominantly Acacia stenophylla and A. salicina) to the burnt site. Control sites were not impacted by the experimental fire, nor any other known disturbances throughout the trial period.

Average NDVI and NBR values across the burnt and control areas were plotted over the time-series to show fire impacts and recovery of vegetation post-fire by comparing control and burnt sites. In order to remove rainfall effects and phenological changes, the post-fire images were standardized to the pre-fire control images using a difference-adding technique [35]. Pre-fire control averages were used as a baseline, and post-fire control imagery was equated to pre-fire values. For example, where post-fire control average NDVI was lower than the pre-fire control average, the difference was added to the post-fire imagery, and zonal statistics extracted. Alternatively, where post-fire imagery average NDVI was higher than the pre-fire control, the difference was subtracted from the post-fire imagery. For each time-step, the same control-difference value was applied to control sites and burnt sites, resulting in imagery that is standardized for rainfall and phenological effects [35].

\subsubsection{Spectral Signatures of Ground Features}

Spectral signatures for ground features were sampled from single pixels at each time-step using ENVI 5.4 (Exelis Visual Information Solutions, Boulder, CO, USA) spectral profile tool. A representative 
homogenous area of buffel grass was sampled at each grassland transect $(n=5)$ and in control (unburnt) areas $(n=5)$, with the same pixels sampled over the four time-steps. Considering the spatial heterogeneity of open woodland transects (which consists of a mix of tree canopy, grass and bare areas), it was decided to sample the most common tree, Acacia stenophylla. Tree canopies at each transect $(n=5)$ were mapped using Trimble Geo7x GNSS units prior to the fire so that canopies could be tracked throughout the time-series. Acacia stenophylla canopies were selected from control (unburnt) areas $(n=5)$ and sampled for the time-series as a comparison. Tree canopies ranged from $\sim 3-5 \mathrm{~m}$ in diameter. Bare areas of bright colored spoil were also sampled within the burn perimeter $(n=5)$. Values for each feature were averaged and graphed with standard error for each time-step.

PIF corrections (Figures A1 and A2) were assessed for regression relationships to determine the magnitude of date-to-date differences. All regressions resulted in sample points that displayed low scatter and with calculated coefficients of determination $\left(\mathrm{r}^{2}\right)$ close to +1 . It was, therefore, assumed that PIF adjustments for the remaining bands would provide negligible changes to final spectral signatures of on-ground features.

\section{Results}

\subsection{Severity and Recovery Maps}

The classification produced by $d$ NDVI resulted in an overall map accuracy of $65 \%$, which indicates an acceptable agreement between field estimates of severity and the modelled $d$ NDVI and an overall satisfactory result (Table 5) [60]. In contrast, the classification produced by $d$ NBR returned a relatively poorer result, with an overall map accuracy of 58\% (Table 6). Producers' accuracy for both classifications was $80 \%$ for unburnt areas and both classifications also recorded high producers' accuracy for the high severity class, with values of $75 \%$ and $73 \%$ for $d$ NDVI and $d$ NBR respectively. The users' accuracies for both classifications for the high severity category was $80 \%$ for $d$ NDVI and $75 \%$ for $d$ NBR.

Table 5. Fire severity error matrix using $d$ NDVI derived from the WorldView-3 dataset.

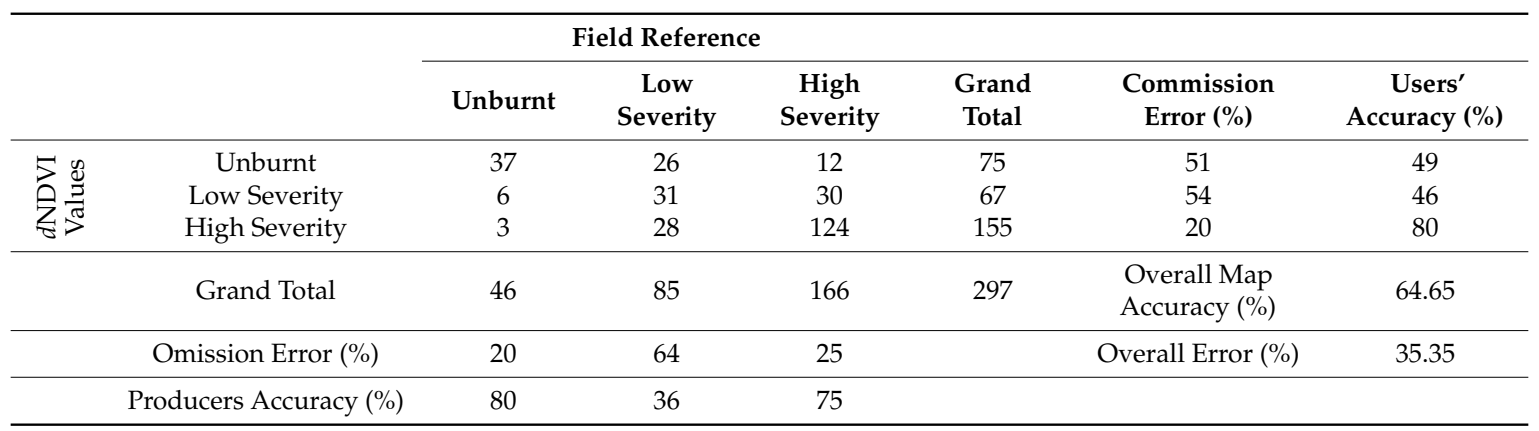

Table 6. Fire severity error matrix using $d$ NBR derived from the WorldView-3 dataset.

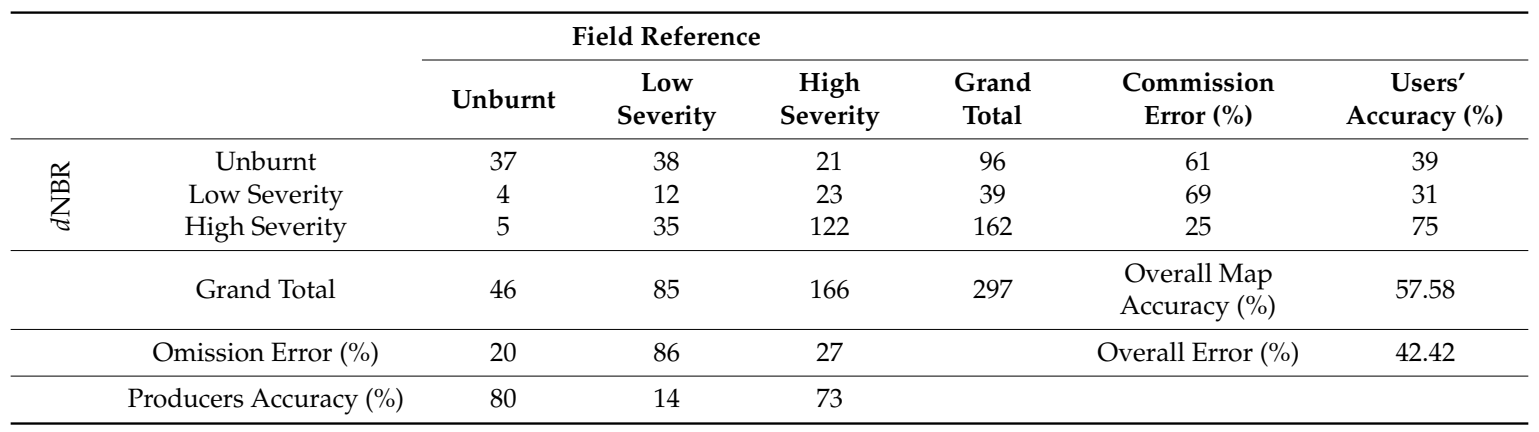

Area analysis of the $d$ NDVI severity map showed that grassland areas had a greater proportion of area impacted by high severity fire (68\%) compared with open woodland areas (39\%). Open woodland 
areas contained a notable proportion of unburnt (33\%) and low severity (28\%) pixels compared with grassland areas (11\% and $21 \%$ respectively) (Table 7 , Figure $4 a$ ).

Recovery maps demonstrated the extent of regrowth of vegetation cover and green biomass (Figure 4). Within 12-months of the fire, $71 \%$ of grassland and $41 \%$ of open woodland areas were classified as high regrowth. This increased by the 24-month post-fire image, with high regrowth across much of the grassland ( $82 \%)$ and open woodland (52\%) areas burnt in the fire (Table 7, Figure $4 \mathrm{~b}, \mathrm{c}$ ). In general, areas that were classified as high severity in the fire severity map, were also classified as high regrowth in the post-fire recovery maps, particularly in the grassland areas.
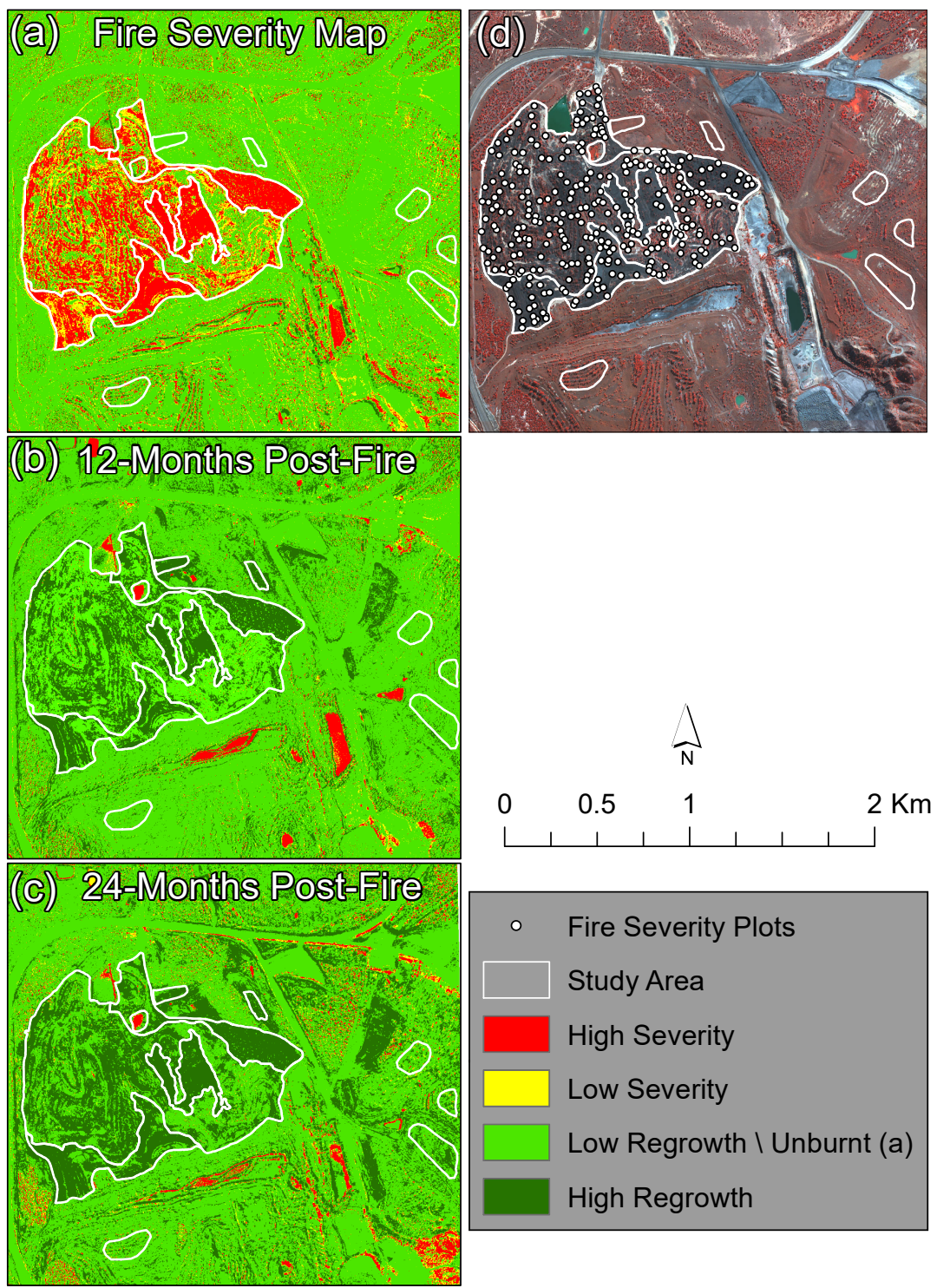

Figure 4. Differenced Normalised Difference Vegetation Index ( $d$ NDVI) analysis of WorldView-3 images showing: (a) fire severity map; (b) fire recovery 12-months post-fire; (c) fire recovery 24-months post-fire and (d) location of ground-based fire severity plots. See Figure 3a for descriptions of grassland and open woodland study area locations. 
Table 7. $d$ NDVI area results for each class for fire severity and recovery maps.

\begin{tabular}{|c|c|c|c|c|c|c|c|}
\hline Map & Location & Metric & High Regrowth & Unburnt/Low Regrowth & Low Severity & High Severity & Total \\
\hline \multirow{6}{*}{$\begin{array}{c}\text { Fire } \\
\text { Severity }\end{array}$} & Whole & Area (ha) & - & 30 & 30 & 57 & 117 \\
\hline & Area & $\%$ & - & 25.64 & 25.64 & 48.72 & 100 \\
\hline & \multirow{2}{*}{ Grassland } & Area (ha) & - & 4 & 8 & 26 & 38 \\
\hline & & $\%$ & - & 10.53 & 21.05 & 68.42 & 100 \\
\hline & Open & Area (ha) & - & 26 & 22 & 31 & 79 \\
\hline & Woodland & $\%$ & - & 32.91 & 27.85 & 39.24 & 100 \\
\hline \multirow{6}{*}{$\begin{array}{l}\text { 12-Month } \\
\text { Fire } \\
\text { Recovery }\end{array}$} & Whole & Area (ha) & 59 & 58 & - & - & 117 \\
\hline & Area & $\%$ & 50.43 & 49.57 & - & - & 100 \\
\hline & \multirow[b]{2}{*}{ Grassland } & Area (ha) & 27 & 11 & - & - & 38 \\
\hline & & $\%$ & 71.05 & 28.95 & - & - & 100 \\
\hline & Open & Area (ha) & 32 & 47 & - & - & 79 \\
\hline & Woodland & $\%$ & 40.51 & 59.49 & - & - & 100 \\
\hline \multirow{6}{*}{$\begin{array}{l}\text { 24-Month } \\
\text { Fire } \\
\text { Recovery }\end{array}$} & Whole & Area (ha) & 72 & 45 & - & - & 117 \\
\hline & Area & $\%$ & 61.54 & 38.46 & - & - & 100 \\
\hline & \multirow[b]{2}{*}{ Grassland } & Area (ha) & 31 & 7 & - & - & 38 \\
\hline & & $\%$ & 81.58 & 18.42 & - & - & 100 \\
\hline & Open & Area (ha) & 41 & 38 & - & - & 79 \\
\hline & Woodland & $\%$ & 51.90 & 48.10 & - & - & 100 \\
\hline
\end{tabular}

\subsection{Field Observations}

Regression analysis shows that NDVI and NBR were negatively correlated with grass curing for both grassland and open woodland areas (Figure $5 \mathrm{a}, \mathrm{c}$ ). This linear relationship is strong and statistically significant for grassland areas for NDVI $\left(\mathrm{r}^{2}=0.80, p=0.00001\right)$ and NBR $\left(\mathrm{r}^{2}=0.86, p=0.000\right)$, where both indices appear to be a good predictor of grassland curing. However, when grassland areas were highly cured in pre-fire assessments $(>70 \%)$, the NDVI is a significantly better predictor of curing $\left(\mathrm{r}^{2}=0.97, p=0.0023\right)$ compared to the NBR $\left(\mathrm{r}^{2}=0.41, p=0.24\right)$. Generally, NBR regression relationships improve as grasses become increasingly greener (wetter) with the highest correlation at 24-months post-fire $\left(\mathrm{r}^{2}=0.88, p=0.021\right)$, while NDVI showed more consistent relationships over the time-series and across the curing spectrum. Note that the surveys were all conducted in the early dry season, so the curing variability throughout the time-series is a response to rainfall rather than any phenological changes or seasonal (drying/greening) cycles associated with perennial and annual grasses. The heterogeneity of open woodland areas resulted in greater variation for transect areas and produced weaker overall trends for NDVI $\left(\mathrm{r}^{2}=0.38, p<0.05\right)$ and NBR $\left(\mathrm{r}^{2}=0.56, p=0.001\right)$ (Figure 5a,c, and Table A1). Note that the post-fire field assessment for curing was not completed, so a trend across the entire time-series is not possible for this metric.

The regression between grass biomass and the tested indices showed a positive, increasing trend for both grassland and open woodland areas (Figure 5b,d). Although scatter was high and the overall relationships for both indices was generally poor, both indices showed improved relationships for grassland areas in the 12-month post-fire (NDVI ${ }^{2}=0.71, p=0.07$; NBR $\mathrm{r}^{2}=0.94, p=0.006$ ) and 24-month post-fire (NDVI $r^{2}=0.90, p=0.01$; NBR $r^{2}=0.88, p=0.02$ ) assessments. Open woodland areas generally produced poor regression relationships across the time-series for both NDVI and NBR (Table A1).

Grassland transects showed a significantly higher average oven dry biomass weight in the pre-fire assessment (9.3 $\mathrm{t} / \mathrm{ha}$ ) compared with open woodland transects (5.4 $\mathrm{t} / \mathrm{ha}$ ) (Figure 6). The immediate post-fire assessment suggests that both open woodland and grassland areas received a high severity burn, with biomass values declining to $0.3 \mathrm{t} / \mathrm{ha}$ and $0.2 \mathrm{t} /$ ha respectively. The 3-month post-fire assessment showed a minor biomass regeneration before plateauing to the 6-month post-fire result at $0.9 \mathrm{t} / \mathrm{ha}$ for open woodland and $0.7 \mathrm{t} / \mathrm{ha}$ for grassland transects. Biomass re-accumulation post-fire showed a strong increasing trend from 6 months post-fire to the final 24 month post-fire time-step, with open woodland recovering to reach average biomass values higher than pre-fire levels $(6.9 \mathrm{t} / \mathrm{ha})$ and average grassland values approaching pre-fire levels (8.6 t/ha) (Figure 6). 

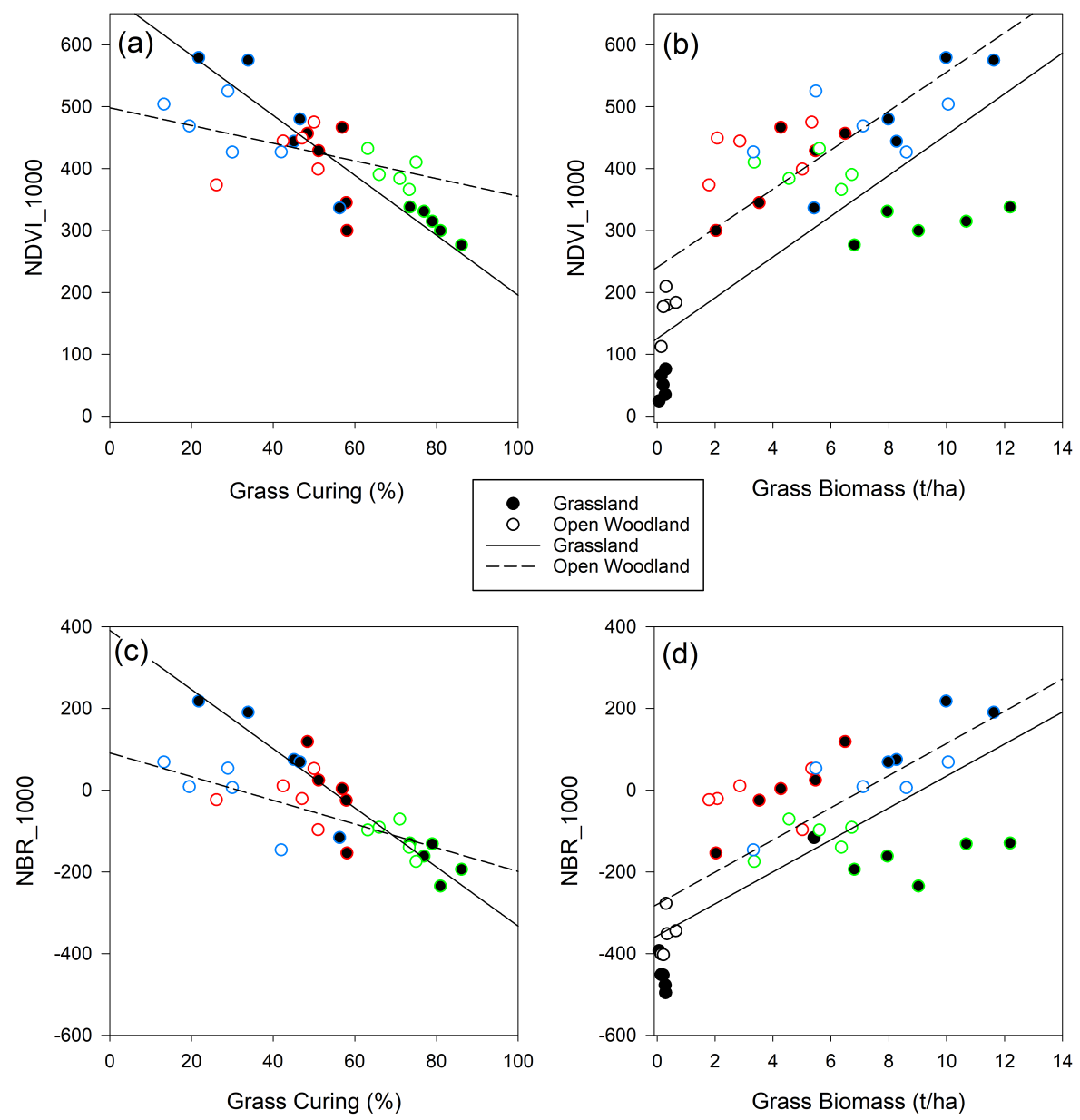

Figure 5. Relationship between vegetation metrics measured at transect locations plotted against average Normalised Difference Vegetation Index (NDVI) and Normalised Burn Ratio (NBR) for transect areas $\left(400 \mathrm{~m}^{2}\right)$ : (a) NDVI vs. grass curing (\%); (b) NDVI vs. grass biomass (t/ha); (c) NBR vs. grass curing $(\%)$ and (d) NBR vs. grass biomass ( $t / h a)$. Green outlines = pre-fire, black outlines = post-fire, red outlines $=12$-months post-fire and blue outlines $=24$-months post-fire. Note that field grass curing was not measured post-fire. For regression statistics and line equations, refer to Table A1.

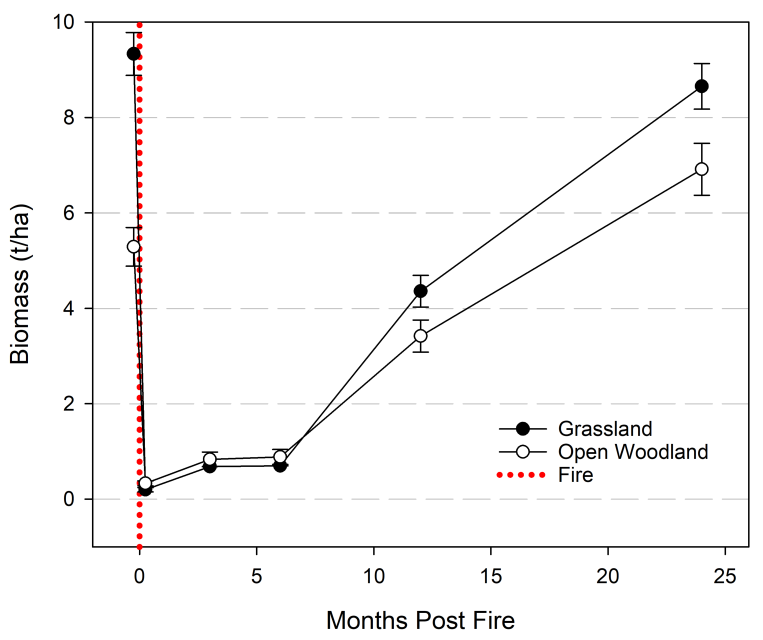

Figure 6. Biomass re-accumulation post-fire for the grassland and open woodland transects. Each point is a quadrat average $\pm \mathrm{SE}(n=50)$. 


\subsection{NDVI and NBR Recovery Trends}

Time-series graphs for both NDVI and NBR demonstrate vegetation recovery of the burnt and unburnt sites in post-fire imagery (Figure 7). Burnt areas of grassland and open woodland show a sharp decline in value, followed by a rapid increase, with both NDVI and NBR recovering beyond pre-fire levels within 12 months of the fire, followed by further growth 24 months post-fire. Likewise, unburnt reference sites show a small decline in NDVI and NBR in post-fire imagery (indicating a drying out of the site), followed by a moderate increase in vegetation condition. Grassland areas responded faster than open woodland areas for both burnt and unburnt sites (Figure 7a,c).

Accounting for rainfall effects and phenology by standardizing the time-series to pre-fire control imagery reveals a reduced recovery trend for both NDVI and NBR in burnt areas. At 24 months post-fire, open woodland had returned to pre-fire levels for both indices. Although grassland was on a recovery trend, both NDVI and NBR show that these areas had not yet returned to pre-fire levels (Figure 7b,d). The apparent decline in NBR grassland at the 24-month post-fire time step indicates that there was a comparatively large increase in the control area for the 24-month post-fire image as compared to the burnt area and is consistent with previous studies [35].
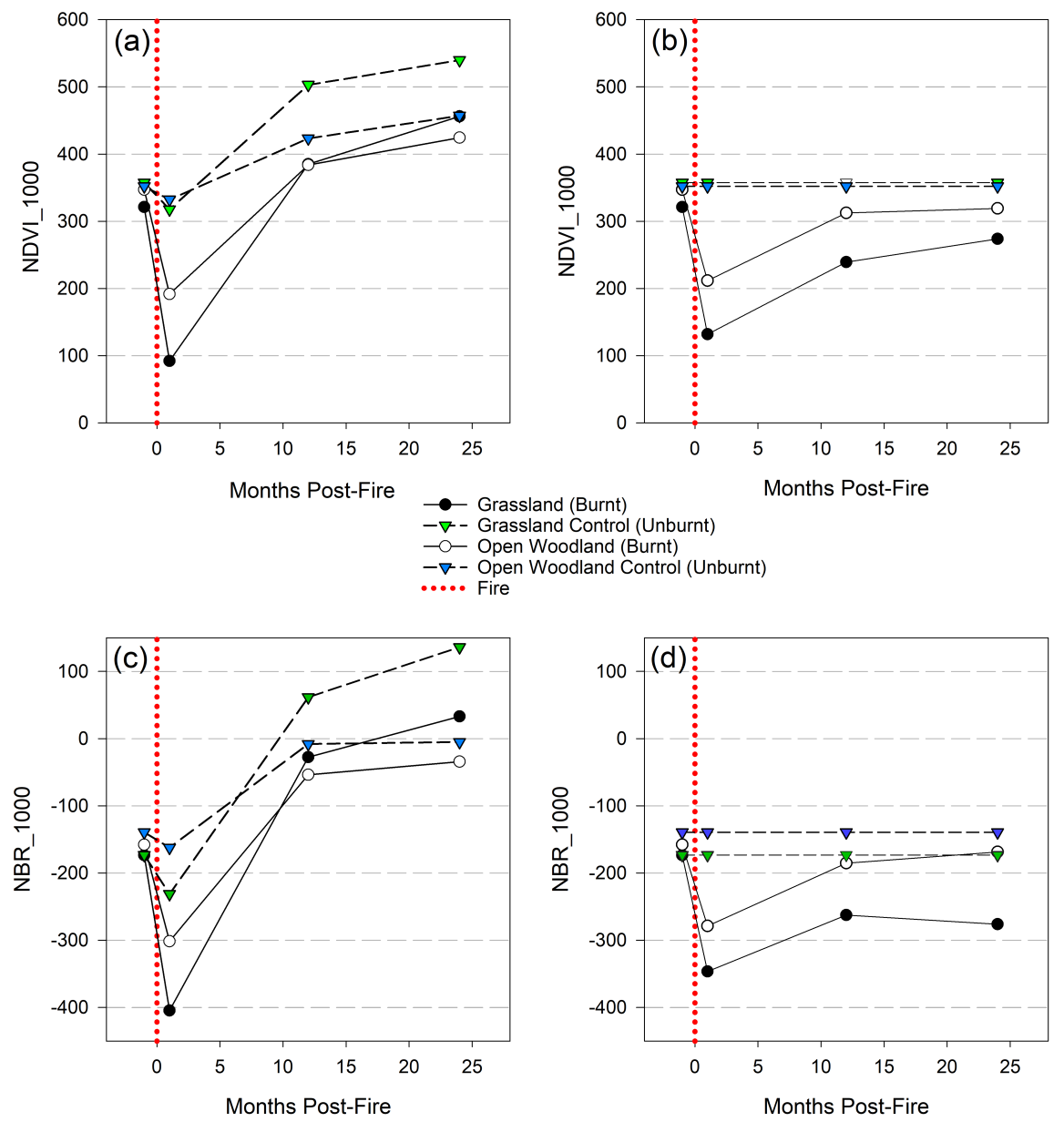

Figure 7. Time-series for recovery post-fire of WorldView-3-derived indices for grassland and open woodland communities using: (a) mean NDVI across entire burnt and unburnt areas (b) standardized mean NDVI of study and control areas (standardized to pre-fire control); (c) mean NBR across entire burnt and unburnt areas; (d) standardized mean NBR of study area and control areas (standardized to pre-fire control). Indices are all scaled to 1000 to assist interpretation. 


\subsection{Spectral Signatures}

Spectral signatures for ground features were sampled across the burnt and unburnt control sites for the pre-fire, post-fire, 12- and 24-month post-fire time-series. Unburnt features from control sites showed only minor variations across the four captures, while burnt features from the study site demonstrated some notable changes due to the fire impact and subsequent vegetation regrowth (Figure 8). Pre-fire spectral signatures show that reflectance values from the study site for buffel grass and Acacia stenophylla were closely aligned with the same features sampled across the control areas (Figure 8a). Buffel grass reflectance was characteristic of cured grasslands, particularly in the longer wavelengths (>1200 nm) where signatures diverged from the reflectance signatures of Acacia stenophylla. The post-fire images reveal that the burnt features strongly contrast with the control features for both buffel grass and Acacia stenophylla. Burnt buffel grass reflectance shows a flat and featureless spectral signature closely resembling black ash, while burnt Acacia stenophylla shows higher variability, due to the range of post-fire canopy conditions experienced by the sample selection (Figure $8 b$ ). The 12- and 24-month post-fire spectral signatures indicate a strong recovery response from buffel grass, mirroring the buffel grass control signature within 12-months post-fire (Figure 8c). The signature for burnt Acacia stenophylla remained below the control signature, particularly in the NIR region of the EMS, for both 12- and 24-month post-fire measurements (Figure 8c,d).

In general, the trends over the time sequence for unburnt control buffel grass and Acacia stenophylla remain relatively steady and consistent. The reflectance signature from bare spoil indicates a consistently high reflectance across the spectrum for each time-step.

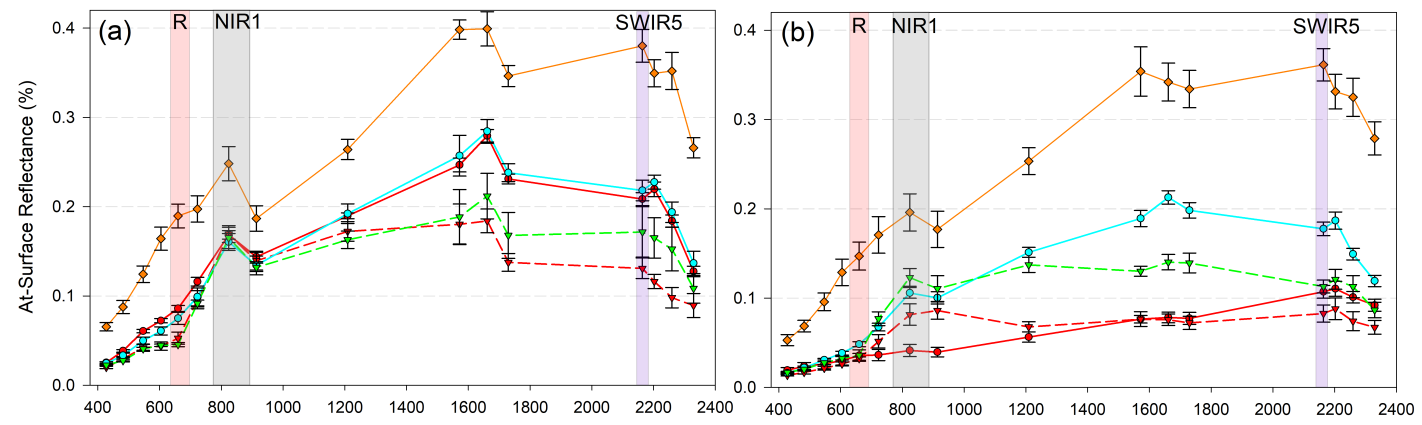

$\multimap-$ Buffel Grass (Burnt) $-\nabla-$ Acacia stenophylla (Burnt) $\multimap-$ Buffel Grass Control (Unburnt) $-\nabla-$ Acacia stenophylla Control (Unburnt) $\multimap$ Bare Spoil

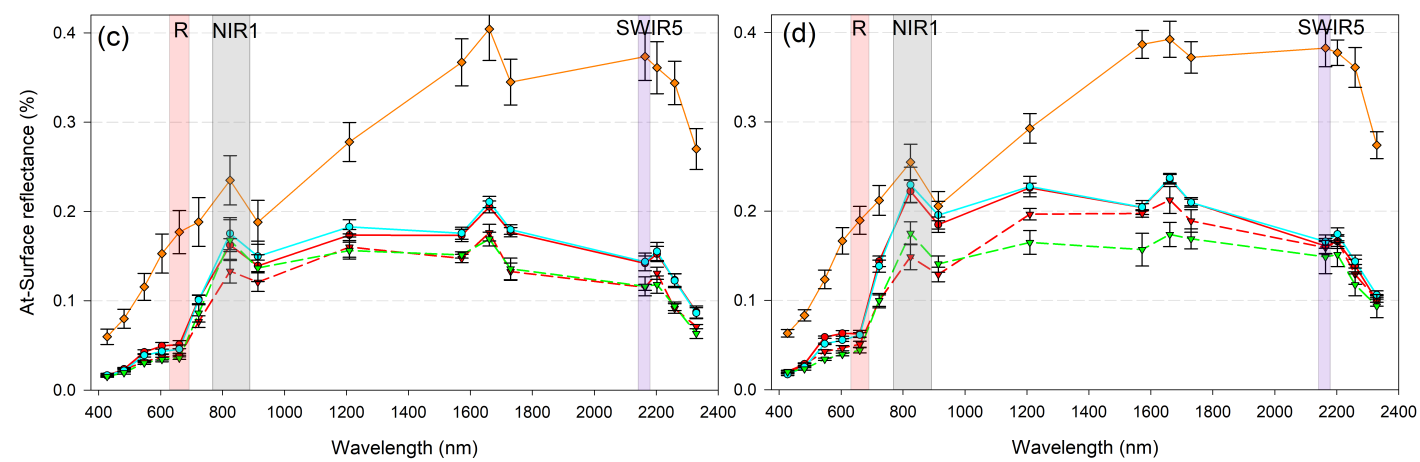

Figure 8. Spectral signatures for ground features in burnt and unburnt (control) areas for the time series: (a) pre-fire imagery; (b) immediate post-fire imagery; (c) 12-months post-fire and (d) 24-months post-fire. Each point represents an average of five locations $\pm \mathrm{SE}$.

\section{Discussion}

This paper demonstrates the post-fire dynamics and vegetation recovery on mine site rehabilitation using a combination of remote sensing and ground metrics. Image analysis provided insights into the fire severity and subsequent recovery through the use of NDVI, $d$ NDVI, NBR and 
$d$ NBR indices over a two-year period. The remote sensing recovery trends, spectral signatures of ground features and in situ grass biomass data suggest that grassland and open woodland areas are on a trajectory towards recovery and are approaching pre-fire levels.

The fire severity maps produced using $d$ NDVI resulted in a higher classification accuracy, and a moderate agreement between the field validation points and the model, as compared to the $d \mathrm{NBR}$ classification. A users' accuracy for the high severity class of $80 \%$ for the $d$ NDVI classification indicates that this map can be useful for rehabilitation managers to assess and monitor the areas of high impact. In general, land managers are most interested in the accurate fire mapping of high severity classes in order to target and monitor any future remediation [18]. Other class accuracies were generally poor for both $d \mathrm{NDVI}$ and $d \mathrm{NBR}$, with high commission and omission errors indicating a significant amount of confusion between the classes. A number of studies have also shown reduced classification accuracies due to overlapping severity classes $[15,18,21,43]$. Common issues involve confusion around low severity impacts due to low vegetation cover, background soil impacts, or drier post-fire imagery providing false positives $[15,21,41,61,62]$. These issues all have the potential to impact on the classification at this site, which contained a heterogeneous vegetation cover on natural black and brown cracking clays and a range of spoil types. Additionally, low rainfall totals leading up to and after the fire are reflected in a noticeably drier post-fire image (Figure 3c, and Figure A3).

Area calculations of the $d$ NDVI severity map demonstrates that the grassland areas received the majority of the high severity impacts, with the open woodland areas showing a mosaic of unburnt, low and high severity (Table 7). This is supported by ground assessments, which showed that the fire consumed a comparatively larger proportion of the understory biomass in the grassland areas. Where the fire was able to move through areas of open woodland, it removed much of the ground layer associated with the topsoil strips along the contour that contained buffel grass at fuel loads equivalent to the more homogenous areas of the grassland type [4].

One of the key outcomes of the study was the improved overall accuracy of the $d$ NDVI classification compared with the $d$ NBR assessment. This is likely due to a number of factors. Firstly, the pre-fire vegetation on the study site was dominated by highly cured grasses and a sparse cover of acacia trees; which proved more suited to indices using the shorter multispectral wavelengths ( $d \mathrm{NDVI})$ as compared with indices utilizing the longer wavelengths of the SWIR region ( $d \mathrm{NBR})$. The $d \mathrm{NBR}$ has been most effective when reflectance values of NIR and SWIR are inverted following fire, whereby NIR exhibits a reduction in reflectance and the SWIR is increased [15]. However, the spectral signatures of ground features measured in this study demonstrated a reduction in both the NIR and SWIR reflectance values in post-fire images, due to the removal of vegetation and presence of black ash, resulting in a poor classification result for $d$ NBR (Figure 8). Changes in the SWIR region of the EMS after burning have been shown to be highly variable across northern Australia [63]; while the $d$ NBR has been demonstrated to work effectively in forested environments [15], it is less effective in savanna with low tree cover and a highly cured understory [32,64]. Reflectance for vegetation in the longer wavelengths of the SWIR region $(1300-2500 \mathrm{~nm})$ is primarily driven by leaf water content-the higher the leaf water content, the lower the reflectance $[25,44]$ - this results in a low spectral response for dense tree canopies, while highly cured grasslands typically show a high reflectance in this region [31,32,42], as demonstrated in the pre-fire spectral signature for buffel grass in Figure 8a. Secondly, the presence of a substantial amount of residual ash in post-fire imagery favors multispectral indices such a $d$ NDVI. Previous studies have modelled fire severity variations with spectral response and found that the NIR and red bands were the most effective at classifying severity for the charcoal signal, rather than when bare soil reflectance dominates the post-fire image [41]. Finally, highly heterogeneous sites may be more strongly suited to small spatial scale imagery as compared to the relatively coarse spatial resolution of the SWIR imagery. Spectral mixing in moderate spatial resolution sensors has resulted in spectral confusion and misclassification [36] and other studies have shown higher overall accuracies due to higher spatial resolution imagery [18]. This was tested by resampling the $1.2 \mathrm{~m}$ NDVI rasters to $7 \mathrm{~m}$ and re-running the severity classification. However, the result was a marginal increase in overall 
map accuracy (data not shown) suggesting that in this study, the improved accuracy of the $d$ NDVI classification is more closely aligned to the suitability of multispectral wavelengths over the SWIR wavelengths in the semi-arid environment.

The $d$ NDVI recovery maps show that areas impacted by high severity fire were also more likely to display high regrowth in the 12- and 24-month post-fire images (Figure 4). This result supports previous findings where areas of grassland impacted by high severity fire were also the areas with a high rate of recovery [42]. Following fire, an increase in available nutrients and light will support regrowth from grasses that are able to respond to changing edaphic conditions, provided the grass root crowns are undamaged $[65,66]$. This is particularly relevant for species such as buffel grass with a demonstrated capacity for fire resilience [65], and with root systems that can reach greater than $2 \mathrm{~m}$ in depth [67]. Additionally, the rehabilitation technique that the mine employed resulted in $100 \%$ topsoil coverage of grassland areas [4]. As a result, these areas are likely to have higher soil-water holding capacity and higher nutrient availability facilitating the rapid regrowth of grasses compared with open woodland areas that contain large areas of bare spoil.

This study demonstrates the importance of unburnt control plots for investigating the resilience of ecosystem dynamics, particularly for extended burn severity assessments. Although the use of control plots and paired unburnt plots have been used successfully in remote sensing studies $[35,68]$, there are no standard approaches to fire severity mapping [18]; despite the potential for controls to reduce the phenological and rainfall effects in the analysis and interpretation of a time-series. For example, prior to standardizing, the NDVI and NBR trends suggest that the burnt sites have recovered beyond pre-fire levels for both grassland and open woodland areas, as early as 12 months post-fire (Figure 7a,c). However, it is clear that the control sites also show an improvement in condition as demonstrated in Figures 3,4 and 7, thus demonstrating the need to determine the recovery trend relative to surrounding unburnt areas. Following standardization, a more realistic insight into the post-fire recovery status shows that recovery trends for burnt grassland and open woodland remain on a trajectory towards pre-fire levels, but are yet to reach full recovery for both NDVI and NBR indices. In fact, by removing the estimated rainfall effects that are responsible for the rapid re-greening of grassland areas, open woodland areas appear to demonstrate a faster overall recovery towards pre-fire levels (Figure $7 \mathrm{~b}, \mathrm{~d}$ ). The in situ field biomass observations support this result, showing biomass loads on open woodland transects above pre-fire levels and recovering faster than on grassland transects (Figure 6). This finding suggests that although grassland areas are recovering rapidly (as demonstrated in $d$ NDVI recovery maps), they have still not returned to pre-fire levels. To support this finding, it can be seen that grassland areas were more heavily impacted in the fire as shown by a greater reduction in NDVI and NBR after the burn (Figure $7 \mathrm{a}, \mathrm{c}$ ) and as a result, these areas may take longer to return to pre-fire levels. Additionally, field surveys recorded a high tree mortality in open woodland areas, followed by significant acacia root suckering and buffel grass growth beneath dead canopies (data not shown) and this is likely to contribute to a greater increase in NDVI and NBR values compared to grassland areas.

It is clear that a high proportion of the site recovery occurred within the first 12-month window following the experimental fire. Other grassland fire studies have analyzed time-series recovery within the first six months post-fire with multiple images to show the first recovery steps [42]. Field observations indicate that the biomass recovery occurred in the 6- and 12-month post-fire window (Figures 6 and 9), which for this study site corresponds to the period between the late dry season and the end of the first wet season. Attempts were made to capture imagery during the 6- to 9-month post-fire window, but these were unsuccessful due to cloud cover in the imagery.

Commission errors were evident in the fire severity and recovery maps, with a number of large areas recording high severity that are present outside the burn perimeter. These commission errors were attributable to a number of factors including: (i) water bodies in the imagery that became increasingly wet through the time-series (water bodies have been shown to be confused with burnt areas in previous studies) [69]; (ii) land-cover changes between image captures where earthworks have created bare areas (this is particularly notable in the south east corner of Figure 4c (when compared 
with the same locations in Figure 3c,e)); (iii) increased shadow as a result of topographic variations and sensor viewing angle; and iv) georeferencing errors in areas of extreme topographic variation to the south of the fire site (for example steep road ramp areas associated with mine infrastructure).

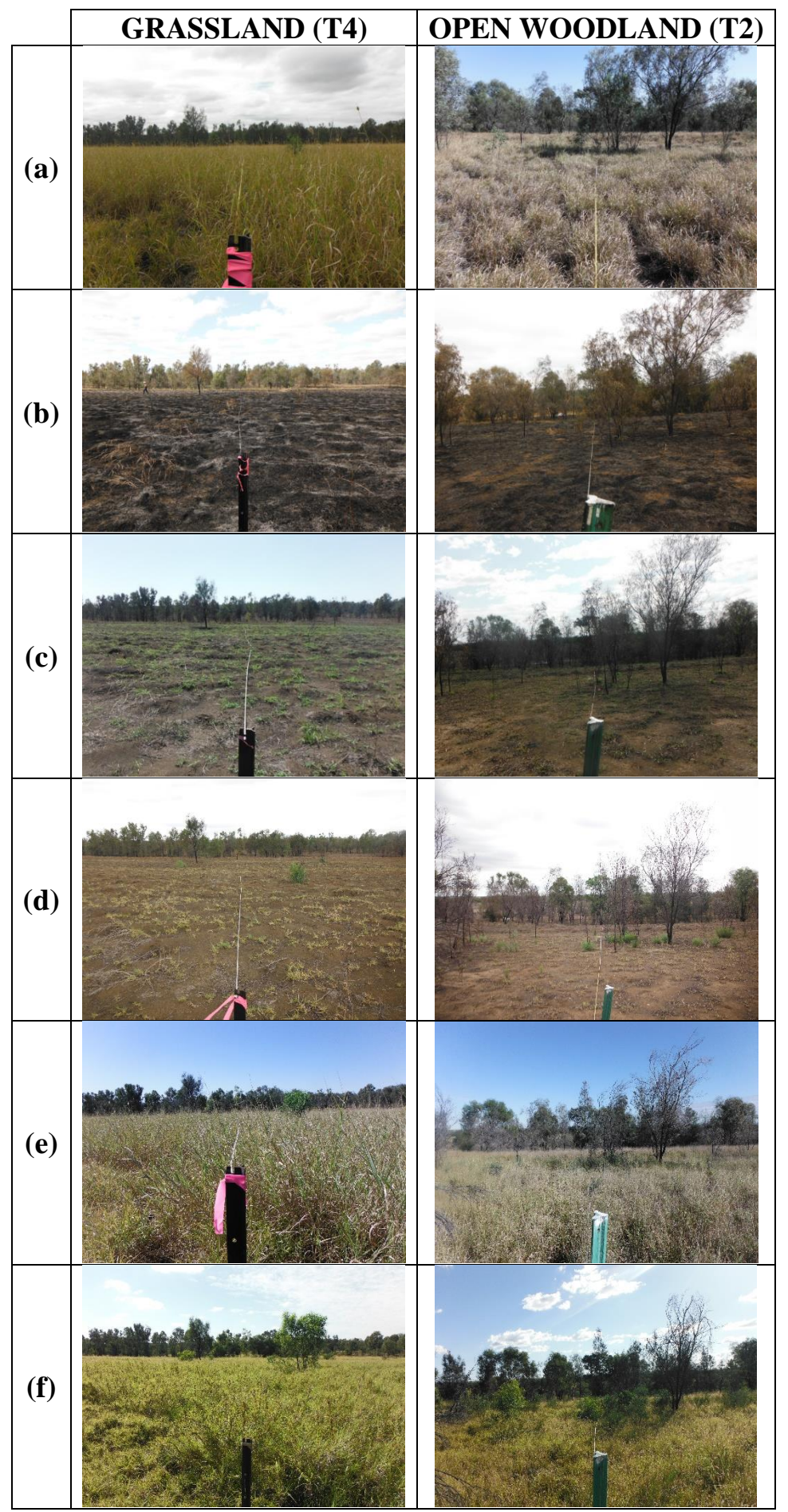

Figure 9. Photographs taken from the start of grassland transect 4 (left) and open woodland transect 2 (right) showing the fire impact and the recovery over the two-year study. Images were taken (a) 7-days pre-fire, (b) 7-days post-fire, (c) 3-months post-fire, (d) 6-months post-fire, (e) 12-months post-fire and (f) 24-months post-fire. Note the death of Acacia stenophylla trees in the open woodland transect followed by the suckering evident in the 24-month image. 
Another limitation to this study includes the timing of the post-fire field severity survey, which was conducted three months after the immediate post-fire image capture. Although this time delay may theoretically be problematic, the dry season conditions resulted in negligible rainfall (Figure A3), and only minor vegetative changes had occurred, such as the initial re-sprouting of buffel grass and first litter fall from some of the impacted trees. Residual ash was still clearly visible across the site, as was charred vegetation and scorched leaves on trees. This is also notable in the relative slow recovery of biomass in the 3- and 6-month post-fire biomass assessments (Figure 6) and field transect photos (Figure 9). However, it is possible that this temporal discrepancy may have contributed to the reduced class accuracy recorded in the low severity and unburnt classes for both indices, due to potential underestimation of fire severity by field workers.

While studies have highlighted heterogeneity of surface features as being problematic for fire mapping in comparable environments such as savanna grasslands and woodland [31,70], this study demonstrates that remote sensing spectral indices can be used to quantify disturbance impacts, vegetation recovery and resilience on highly heterogeneous landscapes. Indeed, the site preparation methods employed during the rehabilitation of coal mine sites within the study region have resulted in fine scale heterogeneity that is unique to rehabilitated landforms, often with no natural analogue. Despite this, the use of high spatial and temporal remote sensing technology to the application of restoration science is highly suited and can be applied at local scales ranging from 1 to $100+\mathrm{km}^{2}$. Further, rehabilitation managers have the opportunity to utilize remote sensing and target approaches to monitoring and remediation for areas that have been impacted by fire, drought, insect attack, flood or cyclone damage and demonstrate to stakeholders the recovery success of rehabilitated areas.

\section{Conclusions}

The accurate assessment of fire risk, disturbance impacts and resilience of rehabilitated lands is vital to mining companies who are tasked with creating and managing the current rehabilitation estate as sites move towards mine closure and future lease relinquishment. When fire impacts occur, managers need to make informed decisions on monitoring and remediation; and remote sensing in combination with targeted field surveys offers informative, cost effective and scientifically robust solutions. The $d \mathrm{NDVI}$ is a suitable index for the assessment of semi-arid grasslands and open woodlands of Central Queensland, and the NIR and red bands appear better suited to resilience analysis when compared to the longer SWIR wavelengths for WorldView-3 products. This study shows the benefits of standardizing time-series trends with nearby, unburnt controls, in order to reduce environmental effects (e.g., rainfall and phenological) and demonstrate more accurate recovery trajectories. The success of the rehabilitation recovery post-fire is likely due to the impact of two significant wet seasons and the future possibility of failed or weak wet seasons on the extended recovery of burnt rehabilitation remain untested.

Author Contributions: P.M., S.P. and P.D.E. conceived and designed the experiments; P.M. performed the experiments and analyzed the data; P.M. wrote the paper with substantial input from S.P., P.D.E.

Funding: The funding for this research was provided by Coronado Curragh Mine Pty Ltd. and the Queensland Resources Council Coal Minesite Rehabilitation Trust Fund Scholarship.

Acknowledgments: Thanks to Vanessa Glenn, Associate Professor Alex Lechner, Associate Professor David Doley and the anonymous reviewers who greatly improved the paper.

Conflicts of Interest: The authors declare no conflict of interest. 
Appendix A

Table A1. Statistics for regression analysis plotted in Figure 5.

\begin{tabular}{|c|c|c|c|c|c|c|c|c|c|c|}
\hline Metric & Figure & Index & Vegetation & Epoch & $\mathrm{n}$ & Equation & $\mathbf{r}$ & $\mathrm{r}^{2}$ & $p$ & Sig \\
\hline Curing & $5 a$ & NDVI & Grassland & All & 15 & $\mathrm{y}=679.8089-4.8442 \mathrm{x}$ & 0.894 & 0.7992 & 0.00001 & yes \\
\hline Curing & $5 a$ & NDVI & Open Woodland & All & 15 & $\mathrm{y}=498.2322-1.4284 \mathrm{x}$ & 0.613 & 0.3757 & 0.0151 & yes \\
\hline Curing & $5 a$ & NDVI & Grassland & Pre-Fire & 5 & $y=-5.1722 x+722.1$ & 0.98455 & 0.96934 & 0.0023 & yes \\
\hline Curing & $5 a$ & NDVI & Grassland & 12-months post-fire & 5 & $y=-10.511 x+971.93$ & 0.63604 & 0.40455 & 0.248683 & no \\
\hline Curing & $5 a$ & NDVI & Grassland & 24-months post-fire & 5 & $y=-7.0186 x+768.57$ & 0.9206 & 0.8475 & 0.026535 & yes \\
\hline Curing & $5 a$ & NDVI & Open Woodland & Pre-Fire & 5 & $y=-2.6542 x+581.55$ & 0.5196 & 0.26998 & 0.369539 & no \\
\hline Curing & $5 a$ & NDVI & Open Woodland & 12-months post-fire & 5 & $y=2.6362 x+314.13$ & 0.65559 & 0.4298 & 0.229682 & no \\
\hline Curing & $5 a$ & NDVI & Open Woodland & 24-months post-fire & 5 & $y=-2.3464 x+532.91$ & 0.57752 & 0.33352 & 0.307896 & no \\
\hline Biomass & $5 b$ & NDVI & Grassland & All & 20 & $y=32.943 x+125.57$ & 0.7675 & 0.58906 & 0.00008 & yes \\
\hline Biomass & $5 b$ & NDVI & Open Woodland & All & 20 & $y=31.565 x+240.77$ & 0.75908 & 0.57621 & 0.000104 & yes \\
\hline Biomass & $5 b$ & NDVI & Grassland & Pre-Fire & 5 & $y=7.8942 x+238.36$ & 0.68403 & 0.46789 & 0.202802 & no \\
\hline Biomass & $5 b$ & NDVI & Grassland & Post-Fire & 5 & $y=105.1 x+29.71$ & 0.46412 & 0.21541 & 0.431019 & no \\
\hline Biomass & $5 \mathrm{~b}$ & NDVI & Grassland & 12-months post-fire & 5 & $y=35.828 x+243.21$ & 0.84196 & 0.7089 & 0.073603 & no \\
\hline Biomass & $5 b$ & NDVI & Grassland & 24-months post-fire & 5 & $y=41.245 x+126.02$ & 0.95001 & 0.90252 & 0.013315 & yes \\
\hline Biomass & $5 b$ & NDVI & Open Woodland & Pre-Fire & 5 & $y=-6.2995 x+430.1$ & 0.34055 & 0.11597 & 0.574936 & no \\
\hline Biomass & $5 b$ & NDVI & Open Woodland & Post-Fire & 5 & $y=89.785 x+142.7$ & 0.48528 & 0.2355 & 0.407311 & no \\
\hline Biomass & $5 b$ & NDVI & Open Woodland & 12-months post-fire & 5 & $y=8.6196 x+398.84$ & 0.34899 & 0.12179 & 0.564846 & no \\
\hline Biomass & $5 b$ & NDVI & Open Woodland & 24-months post-fire & 5 & $y=3.9412 x+443.01$ & 0.23244 & 0.05403 & 0.706736 & no \\
\hline Curing & $5 c$ & NBR & Grassland & All & 15 & $y=-7.2385 x+390.75$ & 0.92679 & 0.85889 & 0.0000 & yes \\
\hline Curing & $5 c$ & NBR & Open Woodland & All & 15 & $\mathrm{y}=-2.9024 \mathrm{x}+90.793$ & 0.74683 & 0.5577 & 0.00138 & yes \\
\hline Curing & $5 c$ & NBR & Grassland & Pre-Fire & 5 & $y=-6.0716 x+310.73$ & 0.64015 & 0.4098 & 0.24465 & no \\
\hline Curing & $5 c$ & NBR & Grassland & 12-months post-fire & 5 & $y=-18.214 x+985.4$ & 0.82067 & 0.6735 & 0.08867 & no \\
\hline Curing & $5 c$ & NBR & Grassland & 24-months post-fire & 5 & $y=-9.2755 x+464.34$ & 0.93147 & 0.8676 & 0.021312 & yes \\
\hline Curing & $5 c$ & NBR & Open Woodland & Pre-Fire & 5 & $y=-5.5465 x+271.45$ & 0.66309 & 0.4397 & 0.222507 & no \\
\hline Curing & $5 c$ & NBR & Open Woodland & 12-months post-fire & 5 & $y=-0.1766 x-8.2268$ & 0.03277 & 0.0011 & 0.958285 & no \\
\hline Curing & $5 c$ & NBR & Open Woodland & 24-months post-fire & 5 & $y=-6.3784 x+168.14$ & 0.82207 & 0.6758 & 0.087652 & no \\
\hline Biomass & $5 \mathrm{~d}$ & NBR & Grassland & All & 20 & $y=39.131 x-356.74$ & 0.71371 & 0.50938 & 0.00041 & yes \\
\hline Biomass & $5 \mathrm{~d}$ & NBR & Open Woodland & All & 20 & $y=39.393 x-279.61$ & 0.74963 & 0.56195 & 0.000142 & yes \\
\hline Biomass & $5 \mathrm{~d}$ & NBR & Grassland & Pre-Fire & 5 & $y=12.84 x-290.46$ & 0.61623 & 0.37973 & 0.268357 & no \\
\hline Biomass & $5 \mathrm{~d}$ & NBR & Grassland & Post-Fire & 5 & $y=-394.26 x-376.34$ & 0.95165 & 0.90564 & 0.012669 & yes \\
\hline Biomass & $5 \mathrm{~d}$ & NBR & Grassland & 12-months post-fire & 5 & $y=53.367 x-374.95$ & 0.97022 & 0.94133 & 0.006141 & yes \\
\hline Biomass & $5 d$ & NBR & Grassland & 24-months post-fire & 5 & $y=55.447 x-248.42$ & 0.94112 & 0.8857 & 0.017 & yes \\
\hline Biomass & $5 \mathrm{~d}$ & NBR & Open Woodland & Pre-Fire & 5 & $y=12.583 x-181.98$ & 0.41539 & 0.17255 & 0.486736 & no \\
\hline Biomass & $5 \mathrm{~d}$ & NBR & Open Woodland & Post-Fire & 5 & $y=103.93 x-390.17$ & 0.3926 & 0.15413 & 0.513282 & no \\
\hline Biomass & $5 \mathrm{~d}$ & NBR & Open Woodland & 12-months post-fire & 5 & $y=0.5874 x-17.884$ & 0.01774 & 0.00031 & 0.977411 & no \\
\hline Biomass & $5 \mathrm{~d}$ & NBR & Open Woodland & 24-months post-fire & 5 & $y=24.382 x-170.76$ & 0.75299 & 0.567 & 0.14178 & no \\
\hline
\end{tabular}



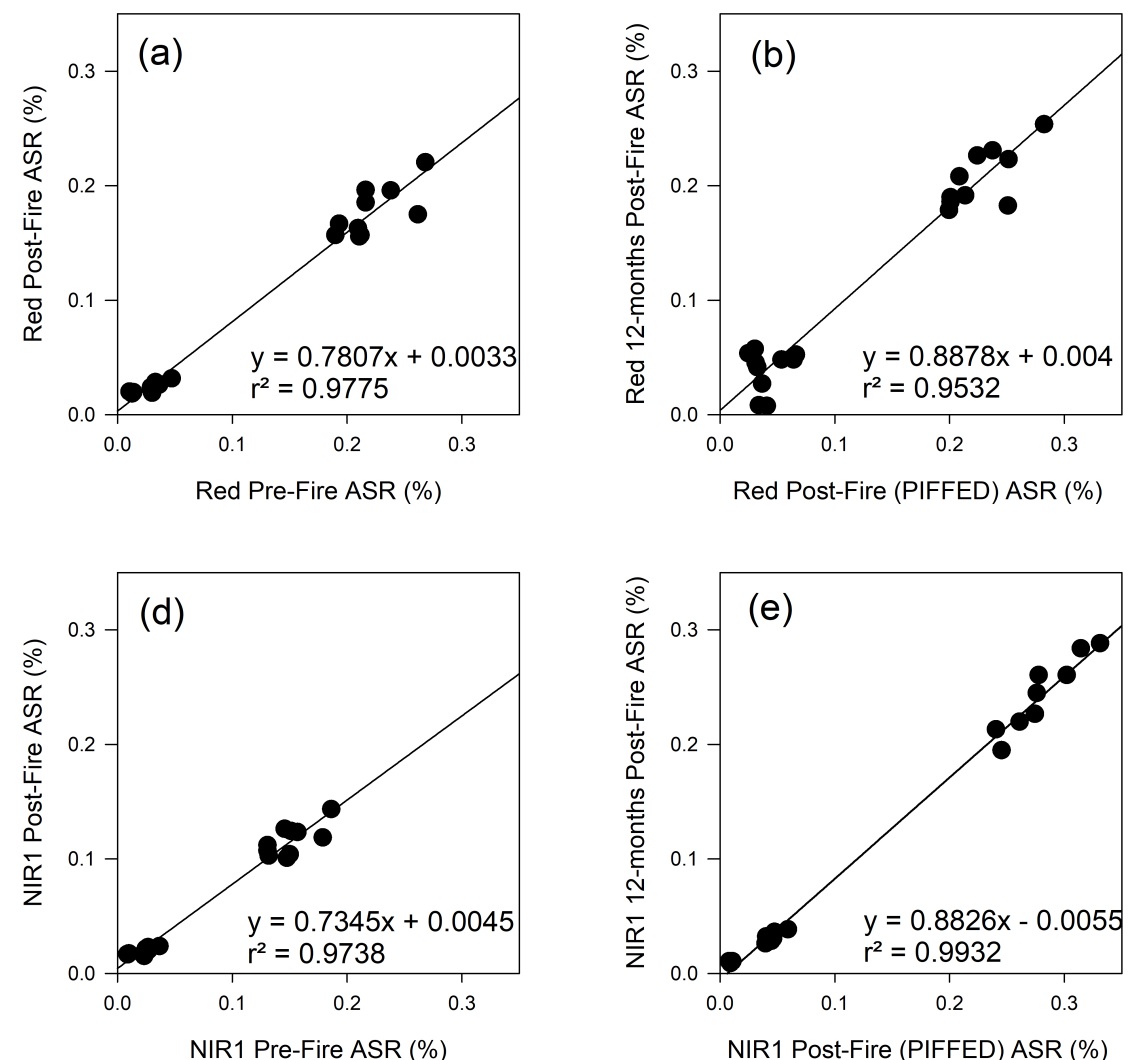
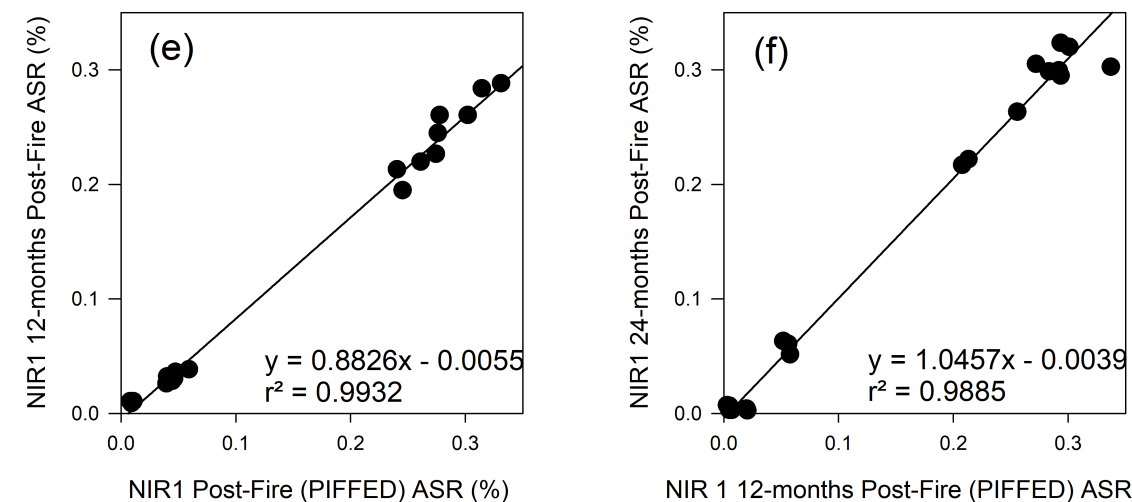

NIR 1 12-months Post-Fire (PIFFED) ASR (\%)

Figure A1. Pseudo Invariant Features (PIF) regressions to normalize the bands used in the NDVI analysis: (a) Red band pre-fire vs. post-fire (b) Red band post-fire vs. 12-months post-fire (c) Red band 12-months post-fire vs. 24-months pot-fire; (d) NIR1 band pre-fire vs. post-fire; (e) NIR1 band post-fire vs. 12-months post-fire and (f) NIR1 band 12-months post-fire vs. 24-months post-fire. ASR = At Surface Reflectance (\%). 

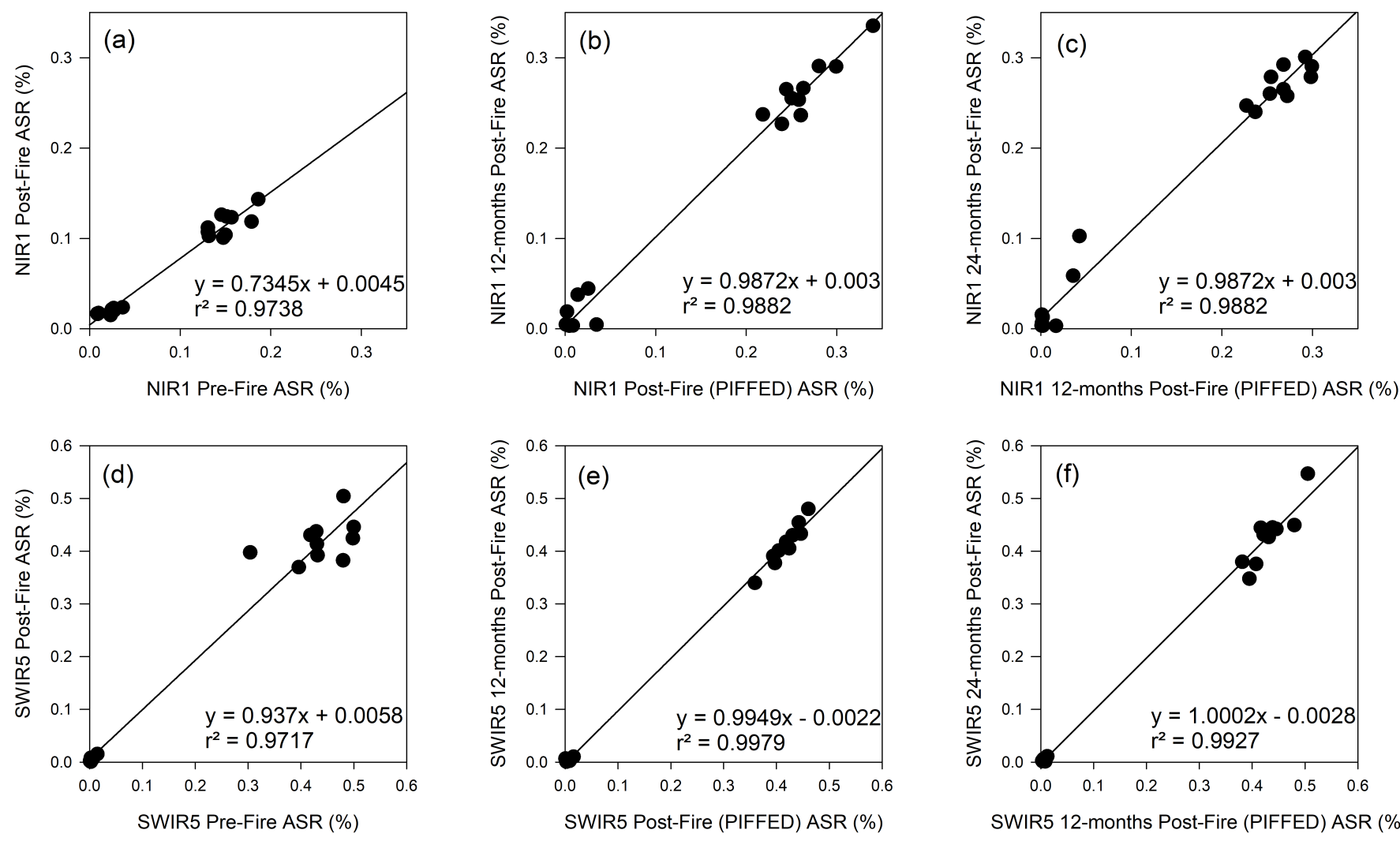

Figure A2. Pseudo Invariant Features (PIF) regressions to normalize the bands used in the NBR analysis. Note that NIR1 bands were resampled to $7 \mathrm{~m}$. (a) NIR1 band pre-fire vs. post-fire (b) NIR1 band post-fire vs. 12-months post-fire (c) NIR1 band 12-months post-fire vs. 24-months pot-fire; (d) SWIR5 band pre-fire vs. post-fire; (e) SWIR5 band post-fire vs. 12-months post-fire and (f) SWIR5 band 12-months post-fire vs. 24-months post-fire. ASR = At Surface Reflectance (\%). 

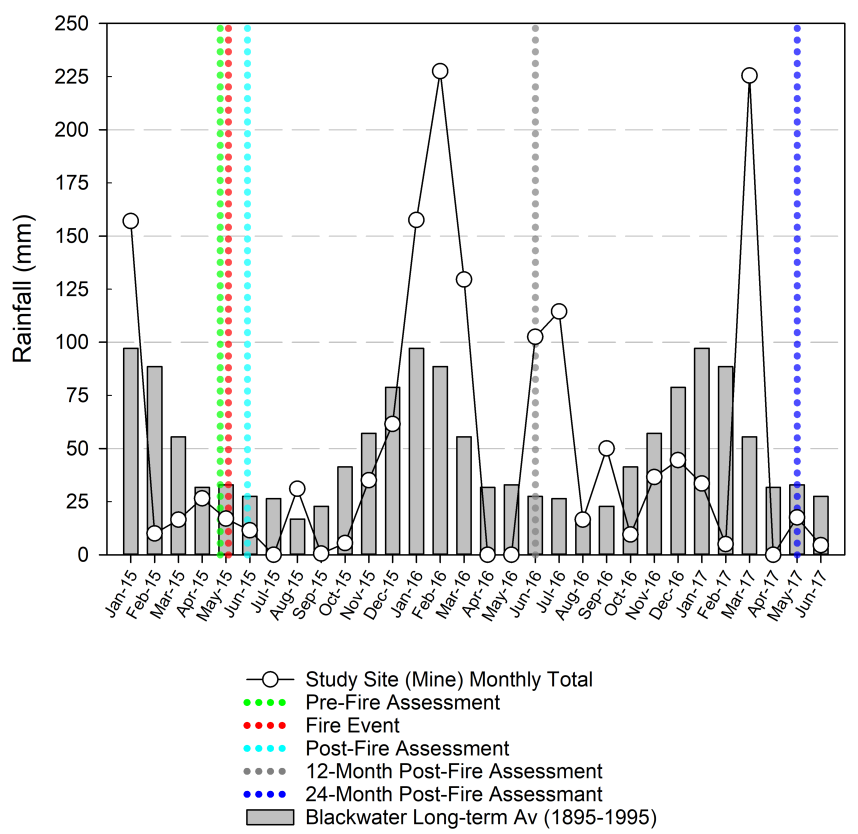

Figure A3. Monthly rainfall measured at the Mine site weather station during the study period compared to the 100-year monthly average taken from the nearby Blackwater Post Office. Source: http:/ / www.bom.gov.au/climate/data/ Dotted lines indicate monitoring events.

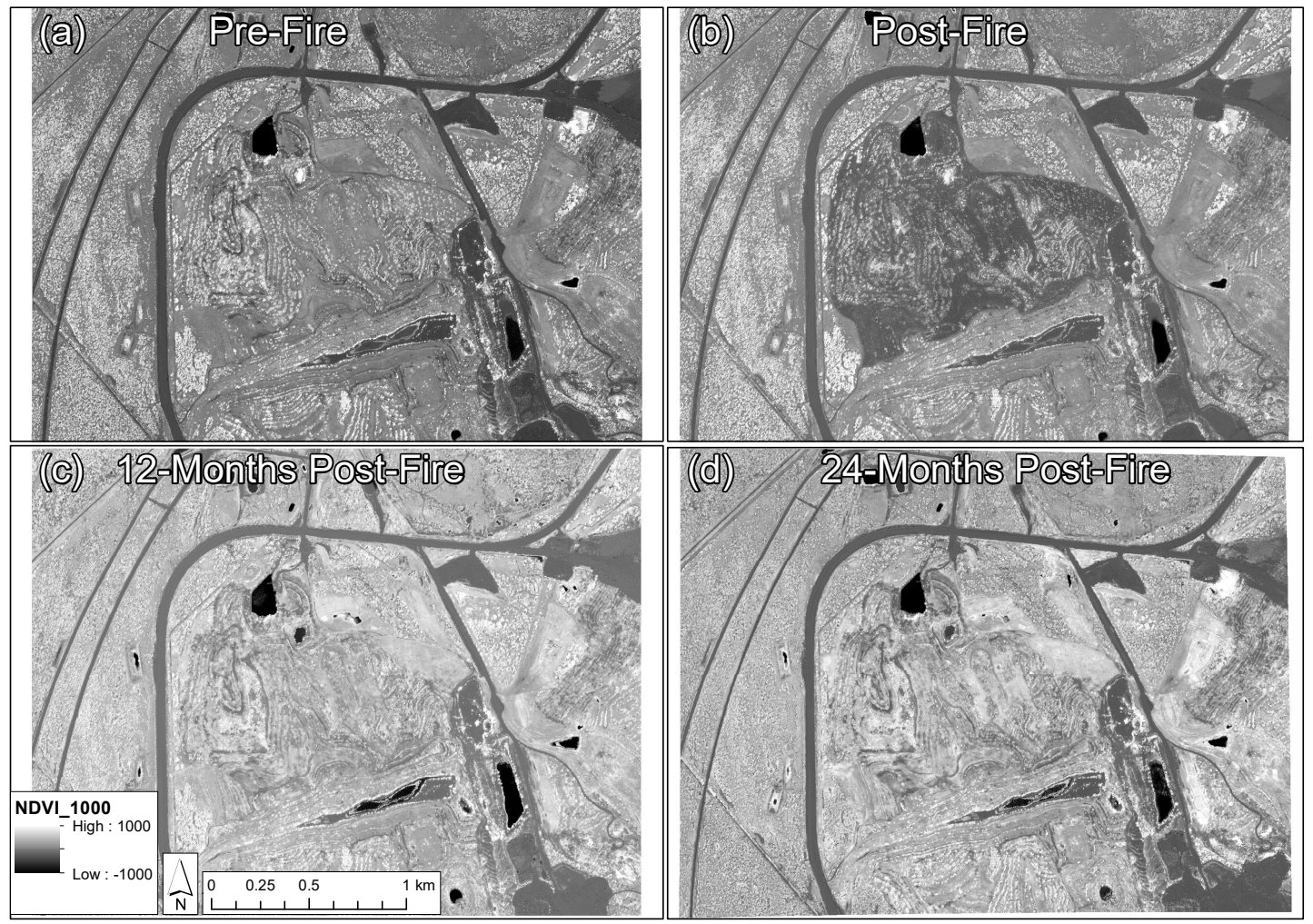

Figure A4. NDVI rasters for the time-series (a) pre-fire; (b) post-fire; (c) 12-months post-fire and (d) 24-months post-fire. 


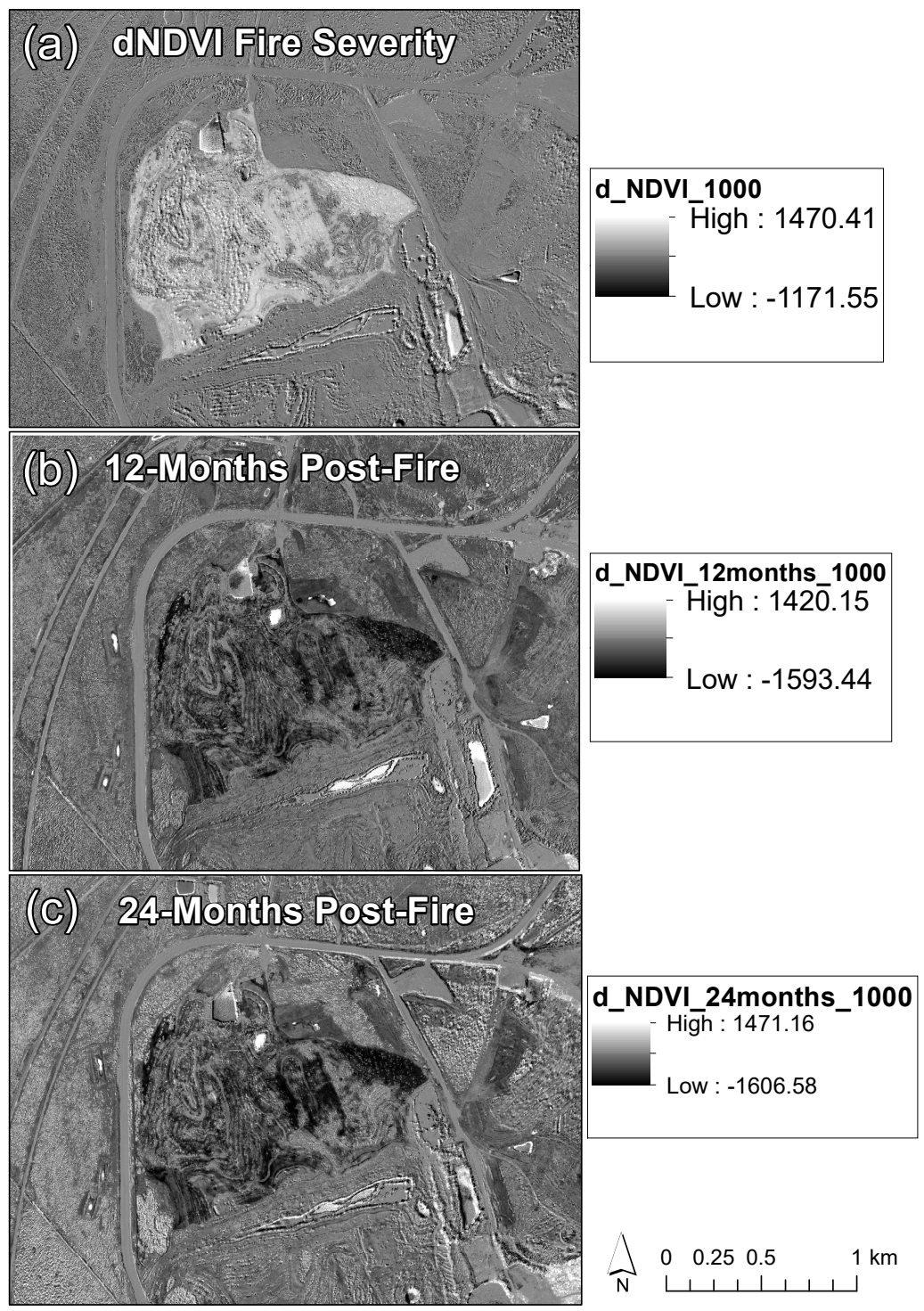

Figure A5. $d$ NDVI rasters for the (a) fire severity map; (b) 12-month recovery map and (c) 24-month recovery map.

\section{References}

1. DEHP. Department of Environment and Heritage Protection, Environmental Authority EPML00643713-Curragh Mine; DEHP: Brisbane, Australia, 2016.

2. Sullivan, A.L.; McCaw, W.L.; Cruz, M.G.; Mathews, S.; Ellis, P.F. Fuel, Fire Weather and Fire Behaviour in Australian Ecosystems. In Flammable Australia Fire Regimes, Biodiversity and Ecosystems in a Changing World; Bradstock, R.A., Gill, A.M., Williams, R.J., Eds.; CSIRO: Collingwood, Australia, 2012; pp. 51-77.

3. Grigg, A.; Shelton, M.; Mullen, B. The Nature and Management of Rehabilitated Pastures on Open-Cut Coal Mines in Central Queensland. Trop. Grassl. 2000, 34, 242-250.

4. McKenna, P.; Glenn, V.; Erskine, P.D.; Doley, D.; Sturgess, A. Fire Behaviour on Engineered Landforms Stabilised with High Biomass Buffel Grass. Ecol. Eng. 2017, 101, 237-246. [CrossRef]

5. Erskine, P.D.; Fletcher, A.T. Novel Ecosystems Created by Coal Mines in Central Queensland's Bowen Basin. Ecol. Process. 2013, 2, 33. [CrossRef]

6. Cook, G.D. Fire Management and Minesite Rehabilitation in a Frequently Burnt Tropical Savanna. Austral Ecol. 2012, 37, 686-692. [CrossRef] 
7. Fletcher, A.T.; Erskine, P.D. Rehabilitation Closure Criteria Assessment Using High Resolution Photogrammetrically Derived Surface Models. Int. Arch. Photogramm. Remote Sens. Spat. Inf. Sci. 2013, XL-1/W2, 137-140. [CrossRef]

8. Lamb, A.D. Earth Observation Technology Applied to Mining -Related Environmental Issues. Min. Technol. 2000, 109, 153-156. [CrossRef]

9. McPherson, J. Perspective from Above. Can. Min. J. 2006, 127, 13-17.

10. Bao, N.; Lechner, A.; Fletcher, A.; Erskine, P.; Mulligan, D.; Bai, Z. SPOTing Long-Term Changes in Vegetation over Short-Term Variability. Int. J. Min. Reclam. Environ. 2012, 28, 2-24. [CrossRef]

11. Bao, N.; Lechner, A.M.; Johansen, K.; Ye, B. Object-Based Classification of Semi-Arid Vegetation to Support Mine Rehabilitation and Monitoring. J. Appl. Remote Sens. 2014, 8, 083564. [CrossRef]

12. Raval, S.; Merton, R.N.; Laurence, D. Satellite Based Mine Rehabilitation Monitoring Using WorldView-2 Imagery. Min. Technol. 2013, 122, 200-207. [CrossRef]

13. McKenna, P.; Erskine, P.D.; Lechner, A.M.; Phinn, S. Measuring Fire Severity Using UAV Imagery in Semi-Arid Central Queensland, Australia. Int. J. Remote Sens. 2017, 38, 4244-4264. [CrossRef]

14. López-García, M.J.; Caselles, V. Mapping Burns and Natural Reforestation Using Thematic Mapper Data. Geocarto Int. 1991, 6, 31-37. [CrossRef]

15. Key, C.H.; Benson, N.C. Landscape Assessment (LA): Sampling and Analysis Methods. In FIREMON: Fire Effects and Monitoring Inventory System; Lutes, D.C., Keane, R.E., Caratti, C.H., Key, C.H., Sutherland, S., Eds.; USDA Forest Service: Fort Collins, CO, USA, 2006; pp. LA-1-LA-55.

16. Jakubauskas, M.E.; Lulla, K.P.; Mausel, P.W. Assessment of Vegetation Change in a Fire-Altered Forest Landscape. Photogramm. Eng. Remote Sens. 1990, 56, 371-377.

17. Frederiksen, P.; Langaas, S.; Mbaye, M. NOAA-A VHRR and GIS-Based Monitoring of Fire Activity in Senegal: A Provosional Methodology and Potential Applications. In Fire in the Tropical Biota: Ecosystem Processes and Global Challenges; Goldammer, J.G., Ed.; Springer-Verlag: Berlin/Heidelberg, Germany, 1990; Volume 84, pp. 400-417.

18. French, N.H.F.; Kasischke, E.S.; Hall, R.J.; Murphy, K.A.; Verbyla, D.L.; Hoy, E.E.; Allen, J.L. Using Landsat Data to Assess Fire and Burn Severity in the North American Boreal Forest Region: An Overview and Summary of Results. Int. J. Wildl. Fire 2008, 17, 443-462. [CrossRef]

19. Keeley, J.E. Fire Intensity, Fire Severity and Burn Severity: A Brief Review and Suggested Usage. Int. J. Wildl. Fire 2009, 18, 116-126. [CrossRef]

20. Jain, T.B. Tongue-Tied: Confused Meanings for Common Fire Terminology Can Lead to Fuels Mismanagement. A New Framework Is Needed to Clarify and Communicate the Concepts. Wildfire 2004, 22-26.

21. Edwards, A.C.; Russell-Smith, J. Measuring and Mapping Fire Severity in the Tropical Savannas. In Savanna Burning: Delivering Carbon and Greenhouse Benefits in Fire Prone Northern Australia; Murphy, B.P., Edwards, A.C., Meyer, C.P., Russell-Smith, J., Eds.; CSIRO Publishing: Melbourne, Australia, 2015; pp. 169-184.

22. Veraverbeke, S.; Lhermitte, S.; Verstraeten, W.W.; Goossens, R. The Temporal Dimension of Differenced Normalized Burn Ratio (DNBR) Fire/Burn Severity Studies: The Case of the Large 2007 Peloponnese Wildfires in Greece. Remote Sens. Environ. 2010, 114, 2548-2563. [CrossRef]

23. Bannari, A.; Morin, D.; Bonn, F.; Huete, A.R. A Review of Vegetation Indices. Remote Sens. Rev. 1995, 13, 95-120. [CrossRef]

24. Tucker, C.J. Red and Photographic Infrared Linear Combinations for Monitoring Vegetation. Remote Sens. Environ. 1979, 8, 127-150. [CrossRef]

25. Jensen, J.R. Remote Sensing of the Environment An Earth Perspective, 2nd ed.; Pearson Education Limited: London, UK, 2014.

26. Robichaud, P.R.; Lewis, S.A.; Laes, D.Y.M.; Hudak, A.T.; Kokaly, R.F.; Zamudio, J.A. Postfire Soil Burn Severity Mapping with Hyperspectral Image Unmixing. Remote Sens. Environ. 2007, 108, 467-480. [CrossRef]

27. White, J.D.; Ryan, K.C.; Key, C.C.; Running, S.W. Remote Sensing of Forest Fire Severity and Vegetation Recovery. Int. J. Wildl. Fire 1996, 6, 125-136. [CrossRef]

28. Chu, T.; Guo, X. Remote Sensing Techniques in Monitoring Post-Fire Effects and Patterns of Forest Recovery in Boreal Forest Regions: A Review. Remote Sens. 2013, 6, 470-520. [CrossRef]

29. Lentile, L.B.; Smith, A.M.S.; Hudak, A.T.; Morgan, P.; Bobbitt, M.J.; Lewis, S.A.; Robichaud, P.R. Remote Sensing for Prediction of 1-Year Post-Fire Ecosystem Condition. Int. J. Wildl. Fire 2009, 18, 594-608. [CrossRef] 
30. Fox, D.M.; Maselli, F.; Carrega, P. Using SPOT Images and Field Sampling to Map Burn Severity and Vegetation Factors Affecting Post Forest Fire Erosion Risk. Catena 2008, 75, 326-335. [CrossRef]

31. Edwards, A.C.; Maier, S.W.; Hutley, L.B.; Williams, R.J.; Russell-Smith, J. Spectral Analysis of Fire Severity in North Australian Tropical Savannas. Remote Sens. Environ. 2013, 136, 56-65. [CrossRef]

32. Maier, S.W. Changes in Surface Reflectance from Wildfires on the Australian Continent Measured by MODIS. Int. J. Remote Sens. 2010, 31, 3161-3176. [CrossRef]

33. Chafer, C.J.; Noonan, M.; Macnaught, E. The Post-Fire Measurement of Fire Severity and Intensity in the Christmas 2001 Syndey Wildfires. Int. J. Wildl. Fire 2004, 13, 227-240. [CrossRef]

34. Hammill, K.A.; Bradstock, R.A. Remote Sensing of Fire Severity in the Blue Mountains: Influence of Vegetation Type and Inferring Fire Intensity. Int. J. Wildl. Fire 2006, 15, 213-226. [CrossRef]

35. Sever, L.; Leach, J.; Bren, L. Remote Sensing of Post-Fire Vegetation Recovery; a Study Using Landsat 5 TM Imagery and NDVI in North-East Victoria. J. Spat. Sci. 2012, 57, 175-191. [CrossRef]

36. Parker, B.M.; Lewis, T.; Srivastava, S.K. Estimation and Evaluation of Multi-Decadal Fire Severity Patterns Using Landsat Sensors. Remote Sens. Environ. 2015, 170, 340-349. [CrossRef]

37. Boer, M.M.; Macfarlane, C.; Norris, J.; Sadler, R.J.; Wallace, J.; Grierson, P.F. Mapping Burned Areas and Burn Severity Patterns in SW Australian Eucalypt Forest Using Remotely-Sensed Changes in Leaf Area Index. Remote Sens. Environ. 2008, 112, 4358-4369. [CrossRef]

38. Walz, Y.; Maier, S.W.; Dech, S.W.; Conrad, C.; Colditz, R.R. Classification of Burn Severity Using Moderate Resolution Imaging Spectroradiometer (MODIS): A Case Study in the Jarrah-Marri Forest of Southwest Western Australia. J. Geophys. Res. 2007, 112. [CrossRef]

39. Gupta, V.; Reinke, K.; Jones, S. Changes in the Spectral Features of Fuel Layers of an Australian Dry Sclerophyll Forest in Response to Prescribed Burning. Int. J. Wildl. Fire 2013, 22, 862. [CrossRef]

40. Tanaka, S.; Kimura, H.; Suga, Y. Preparation of a 1:25000 Landsat Map for Assessment of Burnt Area on Etajima Island. Int. J. Remote Sens. 1983, 4, 17-31. [CrossRef]

41. Chuvieco, E.; Riaño, D.; Danson, F.M.; Martin, P. Use of a Radiative Transfer Model to Simulate the Postfire Spectral Response to Burn Severity. J. Geophys. Res. Biogeosciences 2006, 111, 15. [CrossRef]

42. Lu, B.; He, Y.; Tong, A. Evaluation of Spectral Indices for Estimating Burn Severity in Semiarid Grasslands. Int. J. Wildl. Fire 2016, 25, 147-157. [CrossRef]

43. Smith, A.M.S.; Wooster, M.J.; Drake, N.A.; Dipotso, F.M.; Falkowski, M.J.; Hudak, A.T. Testing the Potential of Multi-Spectral Remote Sensing for Retrospectively Estimating Fire Severity in African Savannahs. Remote Sens. Environ. 2005, 97, 92-115. [CrossRef]

44. Maier, S.W. Modeling the Radiative Transfer in Leaves in the 300nm to 2.5um Wavelength Region Taking into Consideration Chlorophyll Fluorescence-The Leaf Model SLOPE. Ph.D. Thesis, Technische University Munchen, Munich, Germany, 2000.

45. Asner, G.P. Biophysical and Biochemical Sources of Variability in Canopy Reflectance. Remote Sens. Environ. 1998, 64, 234-253. [CrossRef]

46. Elvidge, C.D. Visible and near Infrared Reflectance Characteristics of Dry Plant Materials. Int. J. Remote Sens. 1990, 11, 1775-1795. [CrossRef]

47. Smith, A.M.S.; Hudak, A.T. Estimating Combustion of Large Downed Woody Debris from Residual White Ash. Int. J. Wildl. Fire 2005, 14, 245-248. [CrossRef]

48. Disney, M.I.; Lewis, P.; Gomez-Dans, J.; Roy, D.; Wooster, M.J.; Lajas, D. 3D Radiative Transfer Modelling of Fire Impacts on a Two-Layer Savanna System. Remote Sens. Environ. 2011, 115, 1866-1881. [CrossRef]

49. Bodí, M.B.; Mataix-Solera, J.; Doerr, S.H.; Cerdà, A. The Wettability of Ash from Burned Vegetation and Its Relationship to Mediterranean Plant Species Type, Burn Severity and Total Organic Carbon Content. Geoderma 2011, 160, 599-607. [CrossRef]

50. BOM. Bureau of Meteorology, Australian Government. Available online: http://www.bom.gov.au/climate/ averages/tables/cw_035290.shtml (accessed on 20 April 2018).

51. Anderson, S.A.J.; Anderson, W.R.; Hollis, J.J.; Botha, E.J. A Simple Method for Field-Based Grassland Curing Assessment. Int. J. Wildl. Fire 2011, 20, 804-814. [CrossRef]

52. Haydock, K.P.; Shaw, N.H. The Comparitive Yield Method for Estimating Dry Matter Yield of Pasture. Aust. J. Exp. Agric. Anim. Husb. 1975, 15, 663-670.

53. Walker, J.; Hopkins, M.S. Vegetation. In Australian Soil and Land Survey. Field Handbook; McDonald, R.C., Isbell, R.F., Speight, J.G., Walker, J., Hopkins, M.S., Eds.; Inkata Press: Melbourne, Australia, 1990. 
54. DG (DigitalGlobe). WorldView-3 Data Sheet. 2014. Available online: https:/ /www.spaceimagingme.com/ downloads/sensors/datasheets/DG_WorldView3_DS_2014.pdf (accessed on 20 April 2018).

55. Kuester, M. Radiometric Use of WorldView-3 Imagery Technical Note; DigitalGlobe: Longmont, CO, USA, 2016.

56. Chavez, P.S. An Improved Dark-Object Subtraction Technique for Atmospheric Scattering Correction of Multispectral Data. Remote Sens. Environ. 1988, 24, 459-479. [CrossRef]

57. Hall, F.G.; Strebel, D.E.; Nickeson, J.E.; Goetz, S.J. Radiometric Rectification: Toward a Common Radiometric Response among Multidate, Multisensor Images. Remote Sens. Environ. 1991, 35, 11-27. [CrossRef]

58. Morgan, P.; Keane, R.E.; Dillon, G.K.; Jain, T.B.; Hudak, A.T.; Karau, E.C.; Sikkink, P.G.; Holden, Z.A.; Strand, E.K. Challenges of Assessing Fire and Burn Severity Using Field Measures, Remote Sensing and Modelling. Int. J. Wildl. Fire 2014, 23, 1045. [CrossRef]

59. Congalton, R.G. A Review of Assessing the Accuracy of Classifications of Remotely Sensed Data. Remote Sens. Environ. 1991, 37, 35-46. [CrossRef]

60. Jensen, J.R. Introductory Digital Image Processing A Remote Sensing Perspective, 3rd ed.; Prentice Hall: Upper Saddle River, NJ, USA, 2005.

61. Cocke, A.E.; Fulé, P.Z.; Crouse, J.E. Comparison of Burn Severity Assessments Using Differenced Normalized Burn Ratio and Ground Data. Int. J. Wildl. Fire 2005, 14, 189. [CrossRef]

62. Rogan, J.; Franklin, J. Mapping Wildfire Burn Severity in Southern California Forests and Shrublands Using Enhanced Thematic Mapper Imagery. Geocarto Int. 2001, 16, 91-106. [CrossRef]

63. Maier, S.W.; Russell-Smith, J. Measuring and Monitoring of Contemporary Fire Regimes in Australia Using Satellite Remote Sensing. In Flammable Australia Fire Regimes, Biodiversity and Ecosystmes in a Changing World; Bradstock, R.A., Gill, A.M., Williams, R.J., Eds.; CSIRO: Collingwood, Australia, 2012; pp. 79-95.

64. Goodwin, N.R.; Collett, L.J. Development of an Automated Method for Mapping Fire History Captured in Landsat TM and ETM+ Time Series across Queensland, Australia. Remote Sens. Environ. 2014, 148, $206-221$. [CrossRef]

65. Butler, D.B.; Fairfax, R.J. Buffel Grass and Fire in a Gidgee and Brigalow Woodland: A Case Study from Central Queensland. Ecol. Manag. Restor. 2003, 4, 120-125. [CrossRef]

66. D'Antonio, C.M.; Vitousek, P.M. Biological Invasions by Exotic Grasses, The Grass Fire Cycle and Global Change. Annu. Rev. Ecol. Syst. 1992, 23, 63-87. [CrossRef]

67. Christie, E.K. Physiological Responses of Semiarid Grasses. II The Pattern of Root Growth in Relation to External Phosphorus Concentration. Aust. J. Agric. Res. 1975, 26, 437-446. [CrossRef]

68. Díaz-Delgado, R.; Lloret, F.; Pons, X. Influence of Fire Severity on Plant Regeneration by Means of Remote Sensing Imagery. Int. J. Remote Sens. 2003, 24, 1751-1763. [CrossRef]

69. Escuin, S.; Navarro, R.; Fernández, P. Fire Severity Assessment by Using NBR (Normalized Burn Ratio) and NDVI (Normalized Difference Vegetation Index) Derived from LANDSAT TM/ETM Images. Int. J. Remote Sens. 2008, 29, 1053-1073. [CrossRef]

70. Pereira, J.M.C. Remote Sensing of Burned Areas in Tropical Savannas. Int. J. Wildl. Fire 2003, 12, 259. [CrossRef]

(C) 2018 by the authors. Licensee MDPI, Basel, Switzerland. This article is an open access article distributed under the terms and conditions of the Creative Commons Attribution (CC BY) license (http:// creativecommons.org/licenses/by/4.0/). 